\title{
Rehabilitator's Guide to Diagnostic Postmortem Examination and Gross Pathology in Waterfowl
}

\author{
Natalie Padgurskis ${ }^{1}$, Julia K. Whittington, DVM ${ }^{1}$, Laura Kohrt, DVM, MS ${ }^{2}$ \\ ${ }^{1}$ Department of Veterinary Clinical Medicine, College of Veterinary Medicine, University of Illinois, \\ URBANA, ILLINOIS \\ ${ }^{2}$ Veterinary Diagnostic Laboratory, College of Veterinary Medicine, University of Illinois, \\ URBANA, ILLINOIS
}

\begin{abstract}
Disease monitoring of wild populations gives wildlife professionals and policy-makers valuable information about the health of ecosystems, wild animal populations, and humans. The wildlife rehabilitator is in a unique position to participate in disease monitoring by caring for a random sampling of wild animals presented for care. By detecting infectious disease, wildlife rehabilitators not only are able to protect their facility and hospitalized patients from the introduction of an infectious pathogen, but also are able to assist with wildlife population management. For this reason, it is important for wildlife rehabilitators to be familiar with clinical signs indicative of infectious disease. As migratory species, waterfowl may be useful sentinels for infectious disease outbreaks. Definitive diagnosis of an infectious etiology may be unattainable until the demise of the animal, making postmortem examination essential. Wildlife rehabilitators can become familiar with the normal appearance of internal organs and submit fresh and fixed tissues for further testing, which is less expensive than sending entire birds for necropsy. Necropsy techniques and a few common conditions (botulism, avian cholera, avian influenza, and duck plague) are described.
\end{abstract}

Keywords: waterfowl, postmortem, necropsy, wildlife rehabilitator, wildlife

\section{INTRODUCTION}

It has long been a goal of the wildlife rehabilitator to return sick or injured wildlife to its original condition so that it may be released back into the wild. The role that wildlife rehabilitators play in achieving this goal has become increasingly important due to human encroachment into natural areas, which results

Natalie Padgurskis is a fourth year veterinary student at the University of Illinois College of Veterinary Medicine, class of 2010 . Her area of interest is zoo and wildlife conservation medicine.

Julia Whittington, DVM is a Clinical Assistant Professor of Veterinary Clinical Medicine at the University of Illinois College of Veterinary Medicine. She is Service Chief for the Exotic Pet Service at the Veterinary Teaching Hospital and Director of the Wildlife Medical Clinic.

Laura Kohrt, DVM is a Clinical Assistant Professor and veterinary pathologist at the University of Illinois Veterinary Diagnostic Laboratory. Dr. Kohrt volunteered with the Wildlife Medical Clinic at the University of Illinois for six years and has a continuing interest in the pathology of wild and avian species. in unnatural injuries to wildlife. Additionally, wild animals have been forced to congregate in smaller habitats, concentrated by ecosystem degradation and urban development. Wetlands, for example, have been reduced drastically increasing contact between waterfowl species and subsequently increasing disease spread (Wobeser 1997). Because of their sensitivity and overt response to many pathogens, waterfowl species such as migratory ducks and geese may be useful sentinels or early warning indicators for infectious disease outbreaks (Halliday et al 2007).

Although wildlife rehabilitators overwhelmingly treat trauma victims, they are in a unique position to monitor infectious disease presence in an ecosystem because the wildlife admitted may serve as sentinels (Trocini et al 2008). The type of data collected and quality of record keeping influence the possibility of measuring disease trends in wild populations (Stitt et al 2007). Disease monitoring in wildlife rehabilitation centers may be difficult due to the non-random and biased samples of the animals that are admitted and often insufficient resources limiting diagnostic capabilities (Trocini et al 2008). These confounding factors in disease monitoring necessitate the choosing of a representative animal sentinel to detect disease presence in its natural population. Sentinel populations have characteristics that improve detection of diseases by overtly responding to pathogens in the wild before other species may be affected (McCluskey 2003). Waterfowl species show such a response because of their unique physiology, congregation behavior, and high ecosystem trophic level amplifying susceptibility to pathogens and toxins (Wobeser 1997). With the use of consistent data recording, thorough physical examinations, diagnostic tests, and postmortem examinations, wildlife hospitals can contribute significantly to waterfowl disease monitoring (Sleeman and Clark 2003). In addition, by following proper release proto- 
cols, the rehabilitator helps prevent spread of disease to wild populations (Woodford 2001).

The potential of disease spread among animals under their care should be of utmost importance to wildlife rehabilitators. Strategies to prevent disease should include quarantine, maintaining strict sanitation and hygiene, and performing thorough health screening (Sleeman and Clark 2003). If an infectious disease is suspected within a wildlife hospital, performing a necropsy on affected animals might aid in determining a definitive diagnosis, allowing better treatment for patients and controlling outbreaks. Also, if a reportable or zoonotic disease is detected, the proper steps can be taken to report and prevent further disease spread.

Efficiency of disease detection is enhanced by using proper postmortem examination techniques. The goal of this paper is to provide wildlife rehabilitators with a guide to postmortem examinations in waterfowl and to aid in the detection of infectious diseases, including identification of gross lesions and collection of diagnostic samples to submit for further investigation.

\section{NECROPSY PREPARATION}

Before starting a necropsy, the patient's records, including physical exam findings, history, and pertinent diagnostic test results, are reviewed. Age, sex, and species are taken into consideration, as this information can indicate which diseases to suspect (Schmidt and Reavill 2003). When performing the necropsy, it is important to choose an area that is away from other patients, humans, and food. Make sure the area is well ventilated, as there is always a potential for aerosolization and the transmission of zoonotic pathogens (Porter 2001). Tools that are helpful for necropsy in most birds include a scalpel, forceps, scissors, and a set of poultry, kitchen, or pruning shears. Latex gloves, or similar waterproof hand protection, and protective clothing that can be washed or disposed of after use should be worn. A mask should be worn to prevent inhalation of potential pathogens via aerosol transmission.
During the postmortem exam it is important to record observations thoroughly, describing all lesions and, if possible, taking photographs of interesting lesions. Significant necropsy observations are those that deviate from normal and include changes in size, color, shape, or consistency (Work 2000). These changes represent lesions that could be the result of infectious disease or other pathology. Pictures of normal tissues such as those included in this manual are helpful in identifying lesions, which include any abnormal tissues. Records and photographs may be sent with the tissues to a pathologist familiar with waterfowl and their diseases. Ideally, the entire carcass would be submitted to a qualified pathologist for full postmortem examination when an infectious disease is suspected. However, time and economic restraints may warrant that the rehabilitator perform necropsies inhouse and only submit a selection of tissues. Whole organs can be submitted as well as samples of tissue having representative lesions. Whenever possible, samples of apparently healthy tissue from the same structure should be collected for comparison. Tissue selection is based on the presence of gross (visible) lesions and the anatomical systems that are affected by the suspected disease (Schmidt and Reavill 2003). For example, if Salmonellosis is suspected based on clinical signs and history, the paired intestinal ceca and gastrointestinal tract are collected for submission, as these are the tissues most commonly affected in infected individuals (Figure 1).

Accurate and complete labeling of samples is critical and should include the species, the tissue type or organ of origin, and date of sampling (Ciganovich 1999). Specimen cups, jars, and bottles are useful for

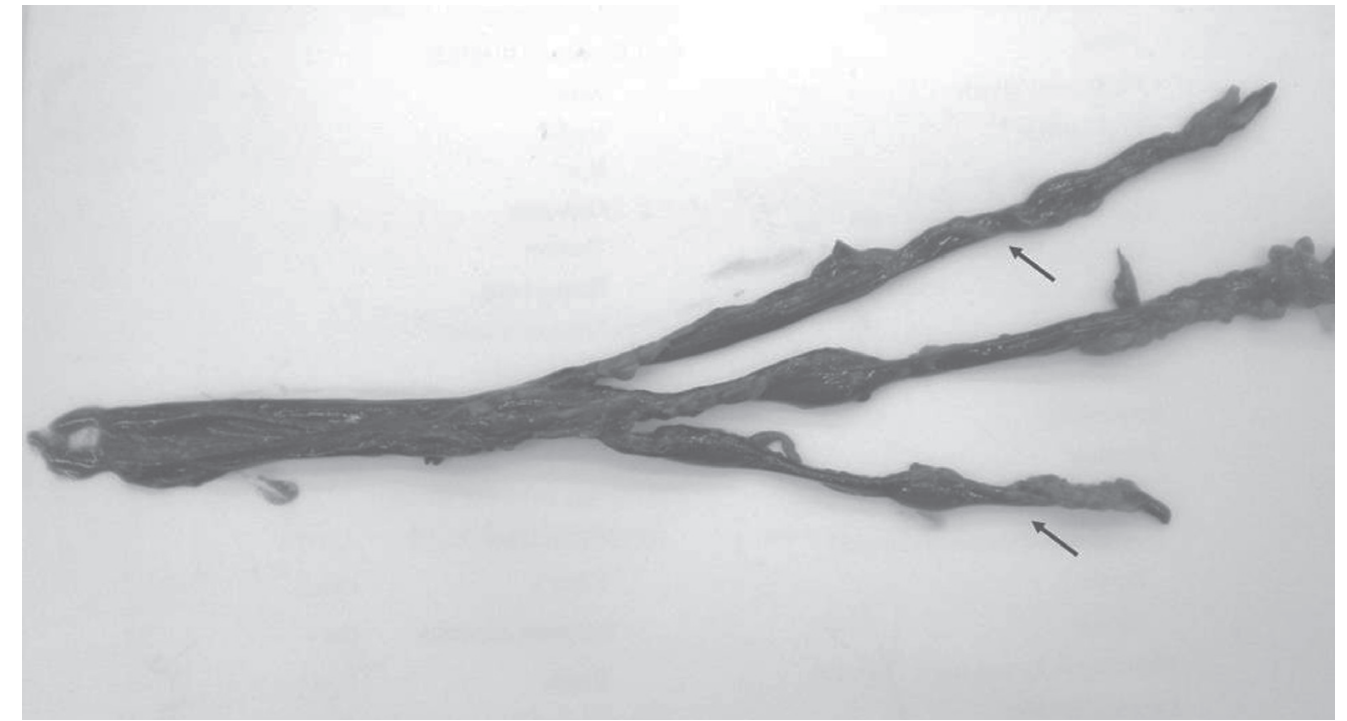

Figure 1. Gastrointestinal tract of a lesser scaup (Aythya affinis) with the small intestine to the right of the picture and the large intestine to the left. The paired ceca are marked with black arrows. 
tissue sample collection as long as they have a wide neck and close securely. Ten percent neutral buffered formalin is the best fixative to preserve tissues, but ethanol or isopropyl alcohol may be used to preserve worms or insect parasites. Most veterinary practices and diagnostic laboratories will have buffered formalin and will be able to supply it to rehabilitators with the proper labeling and storage information. The amount of fixative used is approximately ten times the volume of tissue added. Fixative can only penetrate 5 to 10 $\mathrm{mm}$ into tissues, so thick samples or very dense tissue should be cut in smaller/thinner pieces to allow full penetration of the fixative. Keep specimens chilled in a refrigerator to prevent autolysis (tissue degradation) if the sample will not be fixed in preservative. Avoid freezing and thawing specimens if possible as this can compromise the microscopic appearance of samples. If a viral cause of disease is suspected, small pieces of affected tissue should be collected without fixative for viral testing. These can be placed in a freezer bag, labeled, and frozen for further evaluation. Bacterial causes of disease often require culture of the pathogen for identification. Samples for bacterial culture can be swabs, tissues, fluids, or material collected from the lumens of structures. These samples are placed into airtight containers without fixative and refrigerated prior to and during submission for testing.

Whole carcasses or tissues may be submitted to the United States Geological Survey (USGS) National Wildlife Health Center in Madison, WI, for full diagnostic investigation. It is especially important to contact this facility if a significantly large die-off of wildlife occurs. To contact the appropriate USGS Field Investigation Team before shipping a carcass or samples, call 608-270-2400 or go to <http://www. nwhc.usgs.gov/mortality_events/reporting.jsp>.

\section{NECROPSY PROCEDURE AND TECHNIQUES}

Identification of gross lesions is dependent on recognizing a deviation from what is normal for that tissue in that species. The best way to become familiar with what is normal is to perform postmortem examinations on cadavers of animals that were healthy or had a known cause of mortality such as trauma. When performing postmortem examinations on animals suspected of having infectious disease, any organ that is larger, smaller, misshapen, or discolored from what is normal is removed and submitted to a pathologist for microscopic examination.
[Editor's Note: The definition of various terms used within this paper (cranial, caudal, dorsal, lateral) can be found in the Glossary section of the NWRA Quick Reference, 3rd edition, by Erica A. Miller, DVM.]

External Exam. First inspect the skin and feathers for lesions or abnormalities. Note wear and damage of the tail feathers or wing tips, as these are often indicators of chronic disease and/or time spent on the ground. Observe the vent (opening to the cloaca) and note the presence of fecal accumulation (Figure 2). Healthy birds do not have fecal staining or accumulated material around the vent.

View the ears for signs of infection: redness, swelling, debris, etc. (Figure 3).

Find the uropygial gland on the dorsal aspect of the body just proximal to the tail and inspect it for abnormalities. Feathers surrounding the gland are normally slightly greasy (Figure 4).

Continue inspection of the external body by examining the head, wings, feathers, and feet for lesions (Figure 5). It may be necessary to wet down or remove feathers to visualize the underlying structures.

Internal Exam. The bird is laid on its back and propped or secured such that it will not roll to either side (Figure 6). To ensure stability, one may need to dislocate the legs at the hips by cutting the inguinal (groin) region and forcing them out to either side.

A transverse cut is made in the skin with a scalpel blade between the caudal aspect of the keel and pubis (Figure 7). Once through the skin, continue the incision into the body wall being careful to prevent damage to underlying tissues.

Use fingers and scissors to peel the skin back towards the head (Figure 8a). This allows visualization of the pectoral muscles and better assessment of body condition (Figure 8b).

Use a pair of poultry shears or large scissors to cut the ribs next to the sternum on both sides (Figures 9a and $9 \mathrm{~b})$. Reflect the sternum back towards the head and remove completely with the shears (Figures $9 \mathrm{c}$ and $9 \mathrm{~d})$. This allows better visualization of internal structures.

This duck (Figure 10) has a large syrinx (syringeal bulla), indicating it is male.

Observe the general visceral (internal) anatomy (Figures 11a and 11b). Note any fluid accumulation within the pericardium (around the heart), peritoneum (around the viscera), or in the airsac space. Collect a sample of any fluids for cytology and/or culture in an airtight container. Visualize the airsac membranes that should be transparent and uniform (Figure 12). 


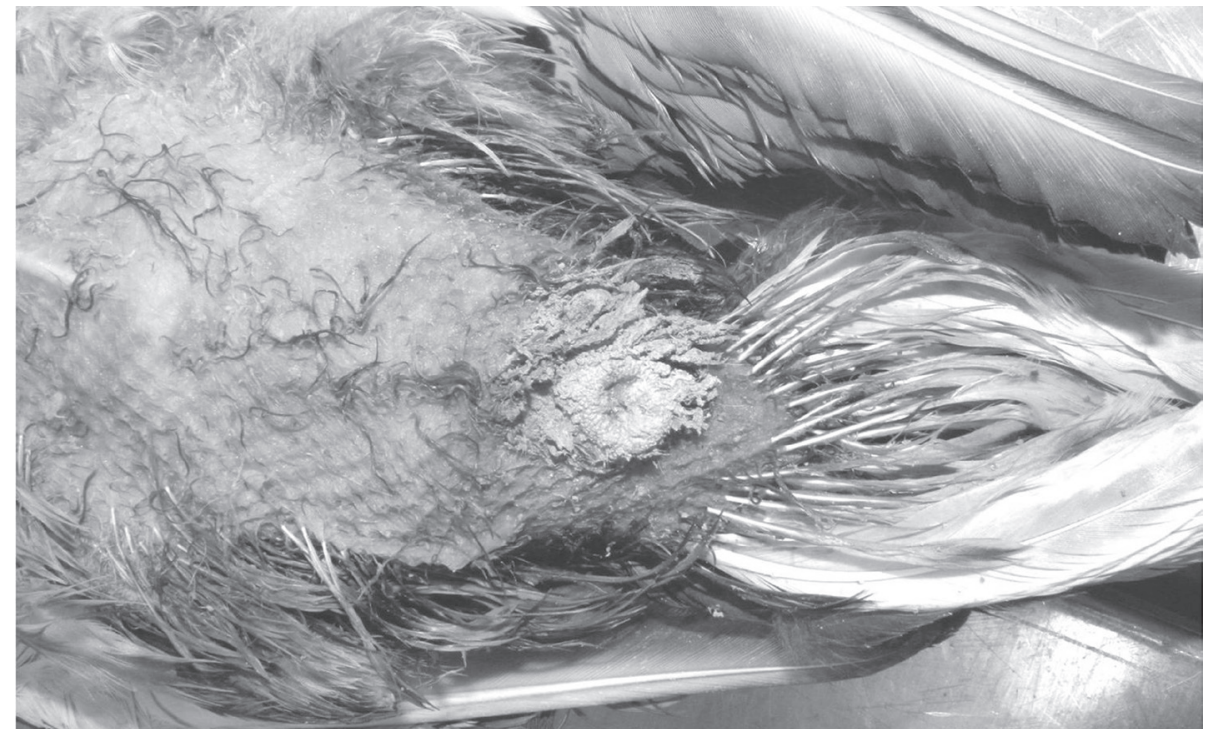

Figure 2. Mallard duck (Anas platyrhynchos) placed in dorsal recumbency with feathers removed from ventrum to reveal area of vent. Head is to the left. Note the accumulation of feces and urates around the vent opening. This duck lost cloacal tone secondary to a spinal fracture.
The gonads are visible once the gastrointestinal viscera have been removed. The hen's ovary is situated on the left side of the coelom with the ovary and developing follicles cranial and medial to the left kidney. The oviduct, which may be difficult to visualize in juveniles and during the non-breeding season, is a thin-walled tubular structure running distally from the ovary to the cloaca. [Editor's Note: Some species, such as the Cooper's hawk (Accipiter cooperii), as well as some individuals, may have paired ovaries and oviducts, with the second ovary cranial and medial to the right kidney.] The male's testes are dark red

If bacterial sepsis is a concern, collect a small quantity of liver without fixative and save the specimen in an airtight container for bacterial culture.

Take the ventriculus (gizzard) and flip it to the left like a page in a book. Underneath lies the spleen that tends to be flattened and triangular in waterfowl (Figure 13).

Remove the gastrointestinal tract and liver as one unit by cutting the esophagus where it enters the thoracic inlet, cranial to the heart, as well as the skin surrounding the vent. This skin is included to ensure that the entire tract is removed. Place a clamp across the esophagus prior to excision to prevent spilling gastrointestinal contents into the coelomic cavity. If toxicosis is suspected, save stomach contents in a sealed waterproof container for further evaluation. Lift out the entire gastrointestinal tract and liver, cutting attachments to the peritoneum as needed, to inspect more thoroughly (Figure 14). Once removed from the coelom, fully explore the entire length of the gastrointestinal tract. Visualize the pancreas as it lies in the space between the duodenal loops (Figure 11b). Evaluate the liver, which is divided into right and left lobes. Check for hemorrhages, white spots, raised lesions, or diffuse changes in the liver tissue. Any abnormal-looking tissue should be submitted to a pathologist. If unsure, collect and submit the entire structure.

Remove the proventriculus (stomach) and ventriculus. The ventriculus tends to be larger, more muscular, and rounder than the proventriculus. Open both with a scalpel to inspect food contents and mucosa (Figure 15). in color and are bilaterally positioned cranial and just medial to the cranial pole of the kidneys.

Examine the surface of the heart noting discoloration or lesions. Remove the heart from the coelomic cavity by cutting the large vessels at the cardiac base (cranially).

Examine the lungs and kidneys as they sit adjacent to the dorsal body wall. The lungs are positioned dorsal to the heart and are not expansive. Lungs should be uniformly light pink with a reticulated pattern. The kidneys are located in the caudal coelom within the renal fossa. Each kidney has three lobes (cranial, middle, and caudal) and is dark red (Figure 16).

After thoroughly inspecting the visceral structures, open up the neck to see the esophagus and crop as well as the trachea (Figure 17).

Use poultry shears to open each side of the bill to visualize oral lesions (Figure 18). Cut between the eye and nostril to detect any nasal discharge or leeches.

Disarticulate the head by cutting between the vertebrae just under the skull. Peel the skin forward towards the beak. While holding the head by the beak, cut away the thin bone at the top of the head to reveal the brain. Place the entire head with skin attached in formalin. 


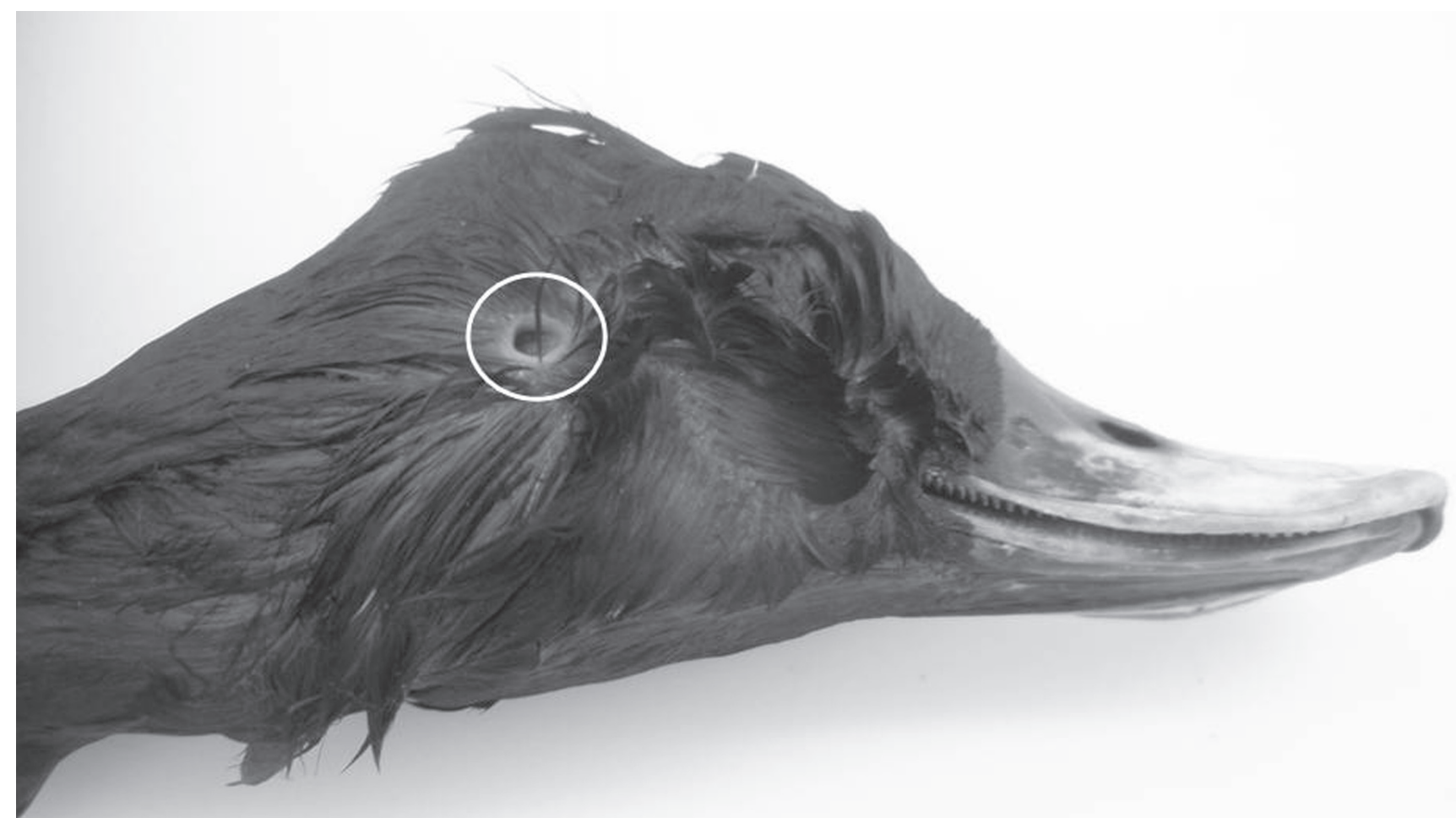

Figure 3. External ear viewed by reflection of feathers. The ear opening is denoted within the white circle.

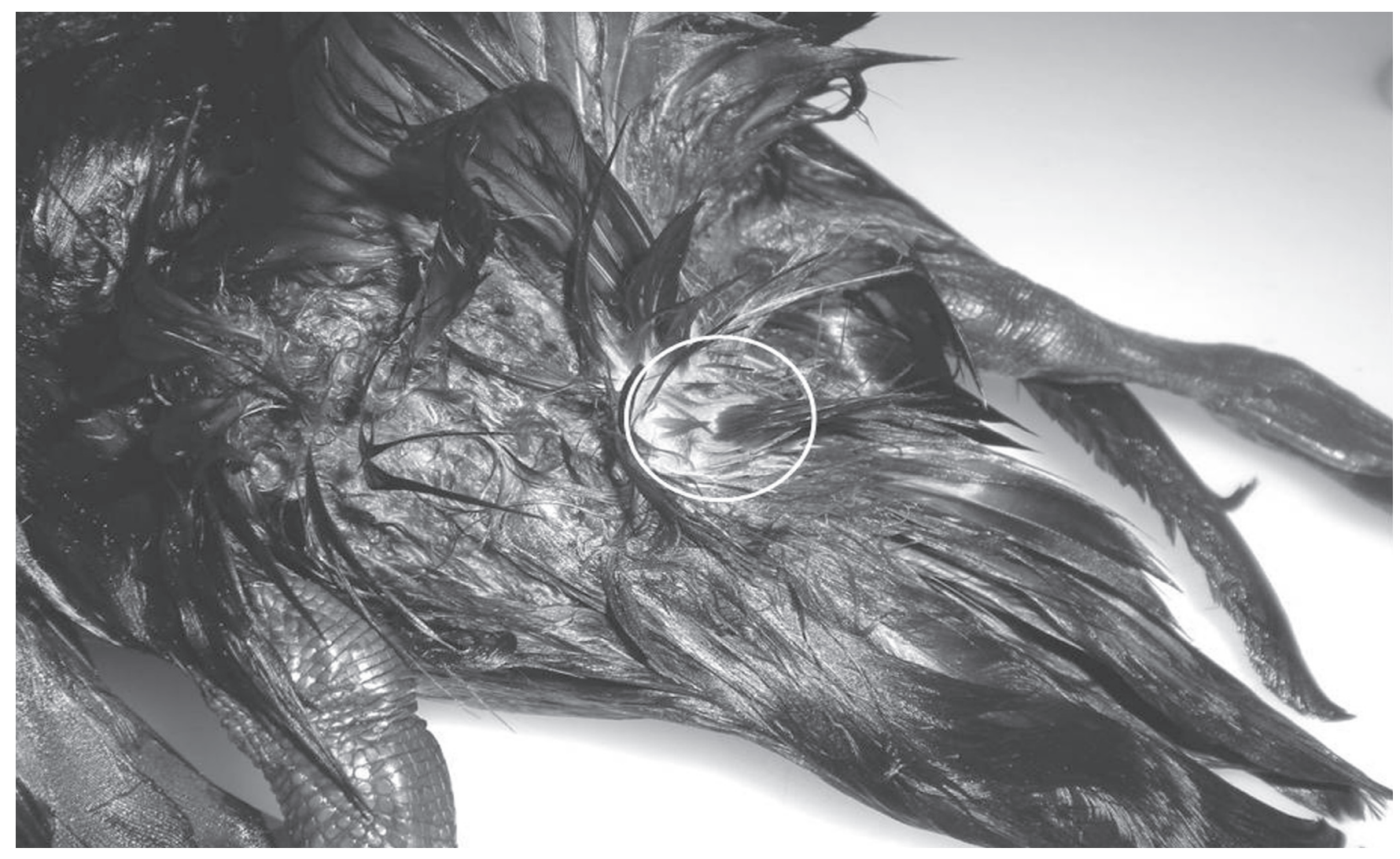

Figure 4. Uropygial gland at the dorsal base of the tail indicated by a white circle. Feathers are reflected for better visualization. 


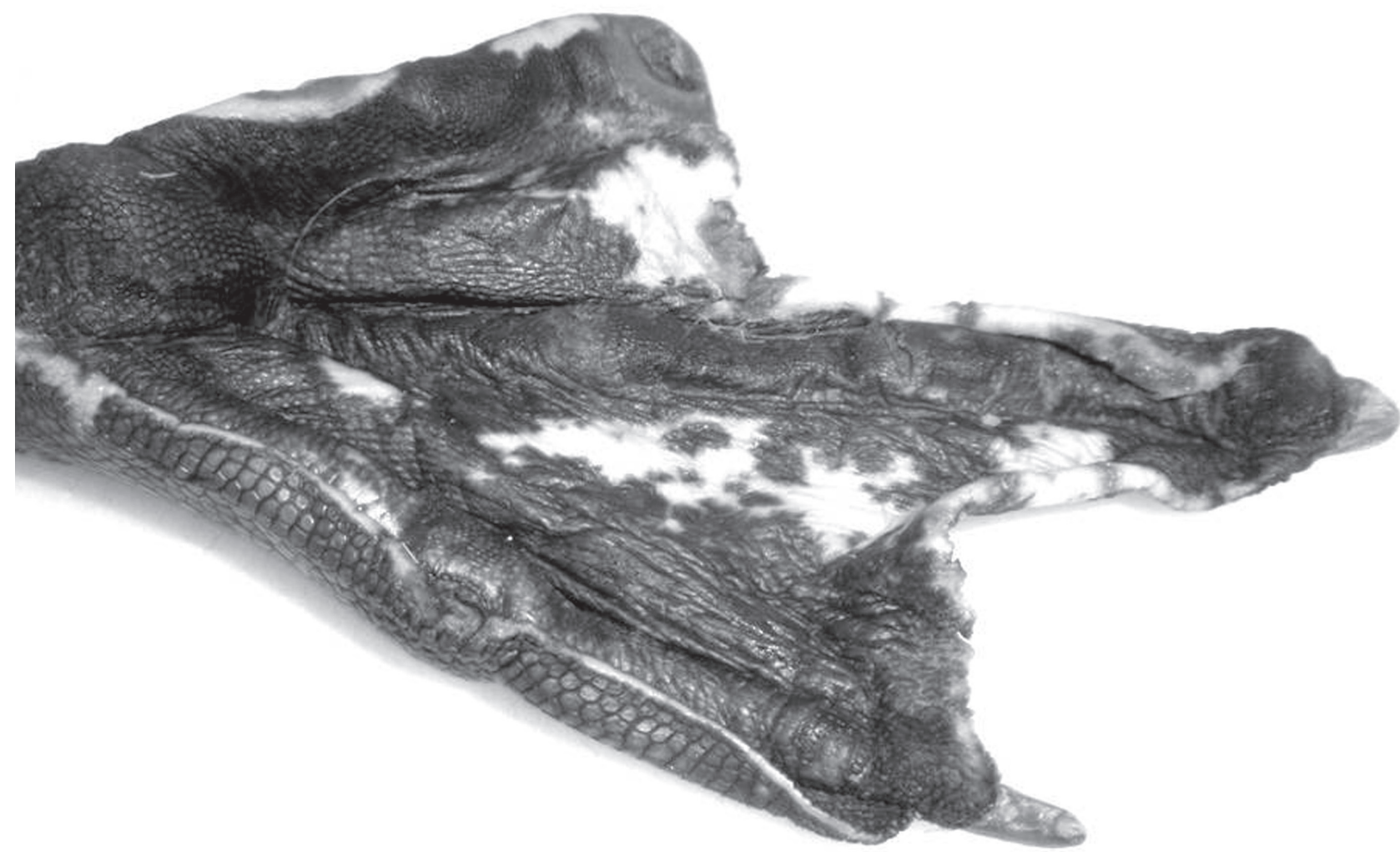

Figure 5. Plantar aspect of the foot of a tundra swan (Cygnus columbianus) affected by pododermatitis, or bumblefoot. A toe was amputated.

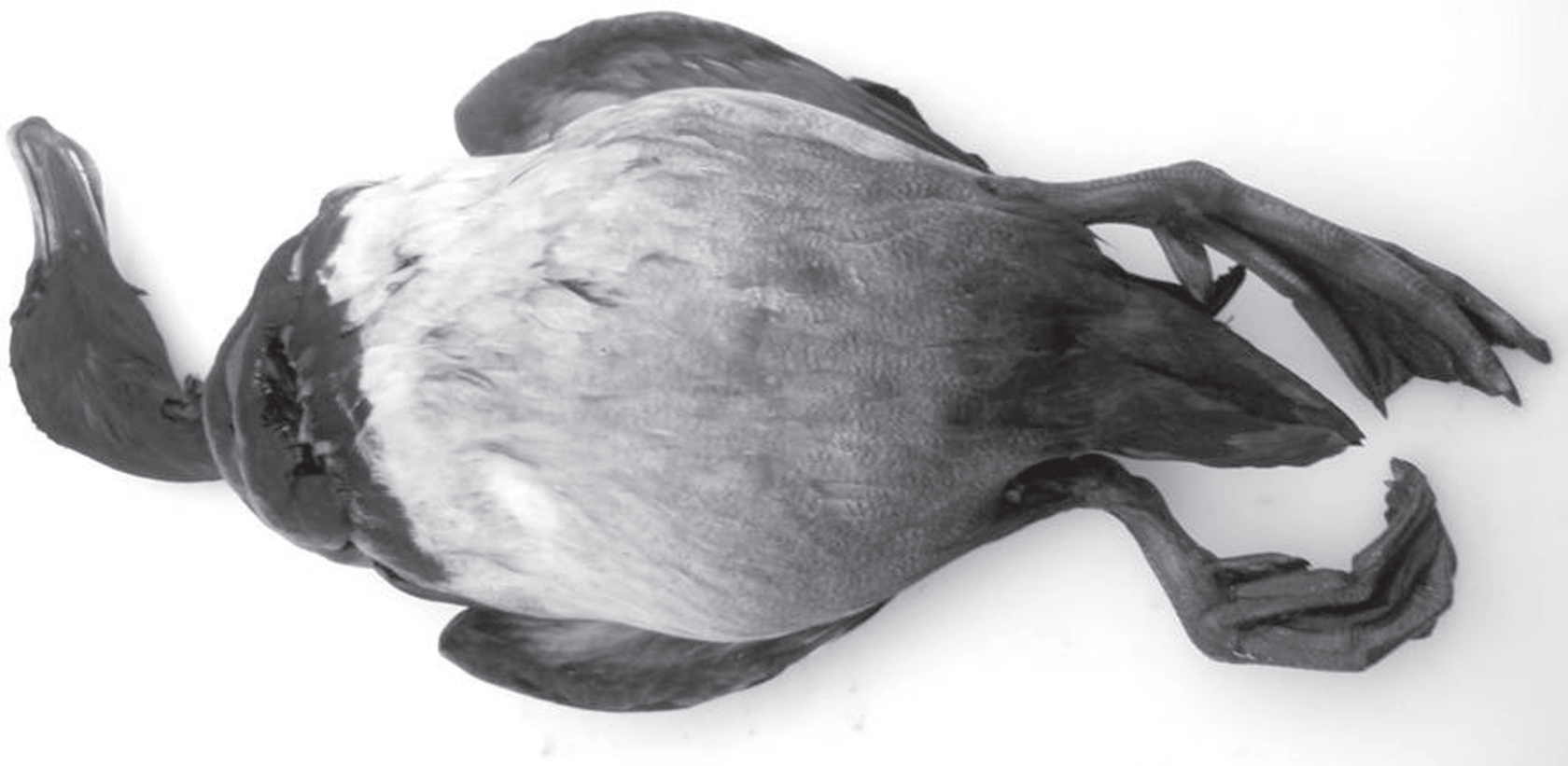

Figure 6. Appropriate positioning of bird before beginning postmortem examination. The bird is lying in dorsal recumbency. 


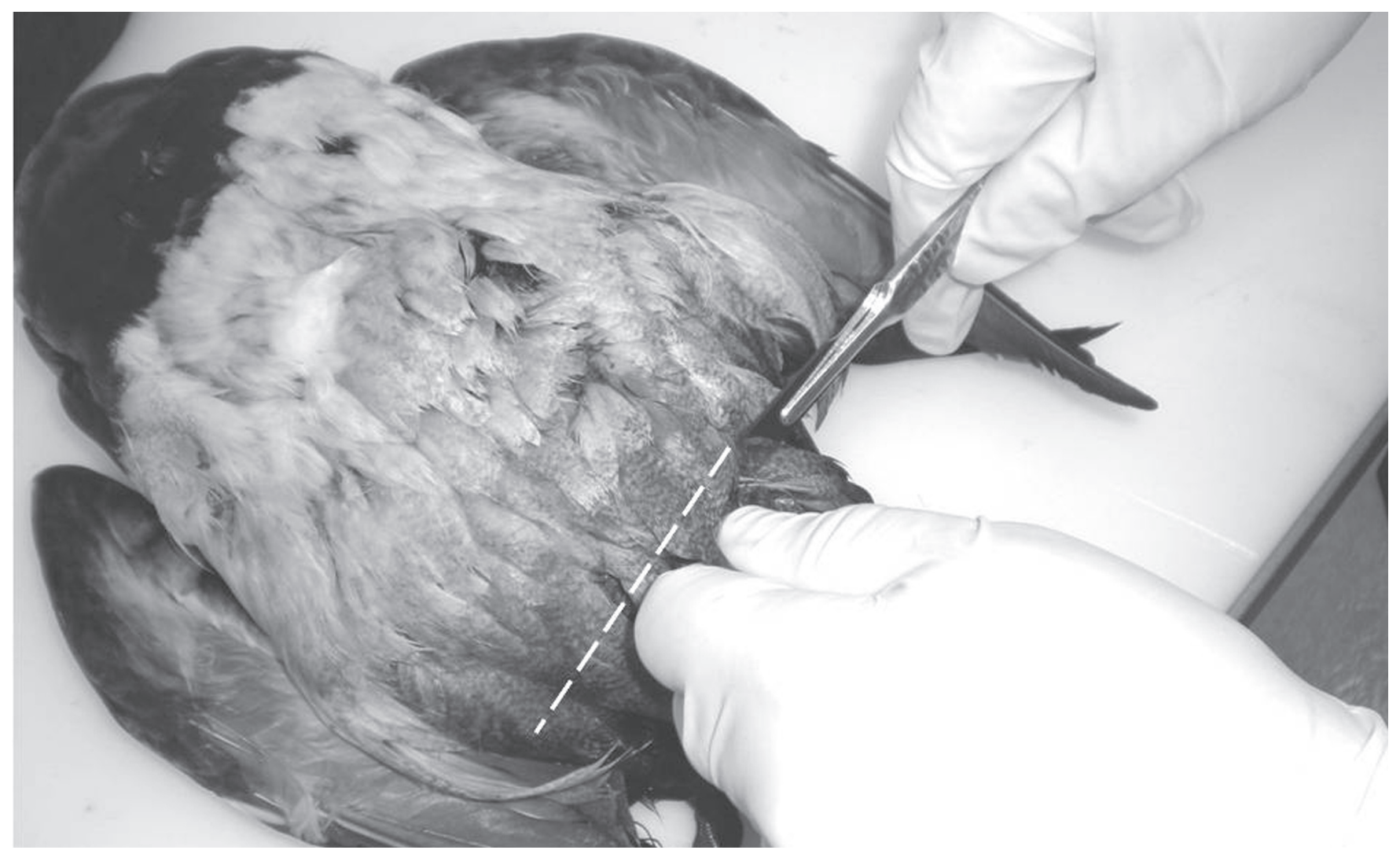

Figure 7. Initial transverse cut with scalpel blade, indicated by dashed line, between sternum and pubis with bird lying on its back.

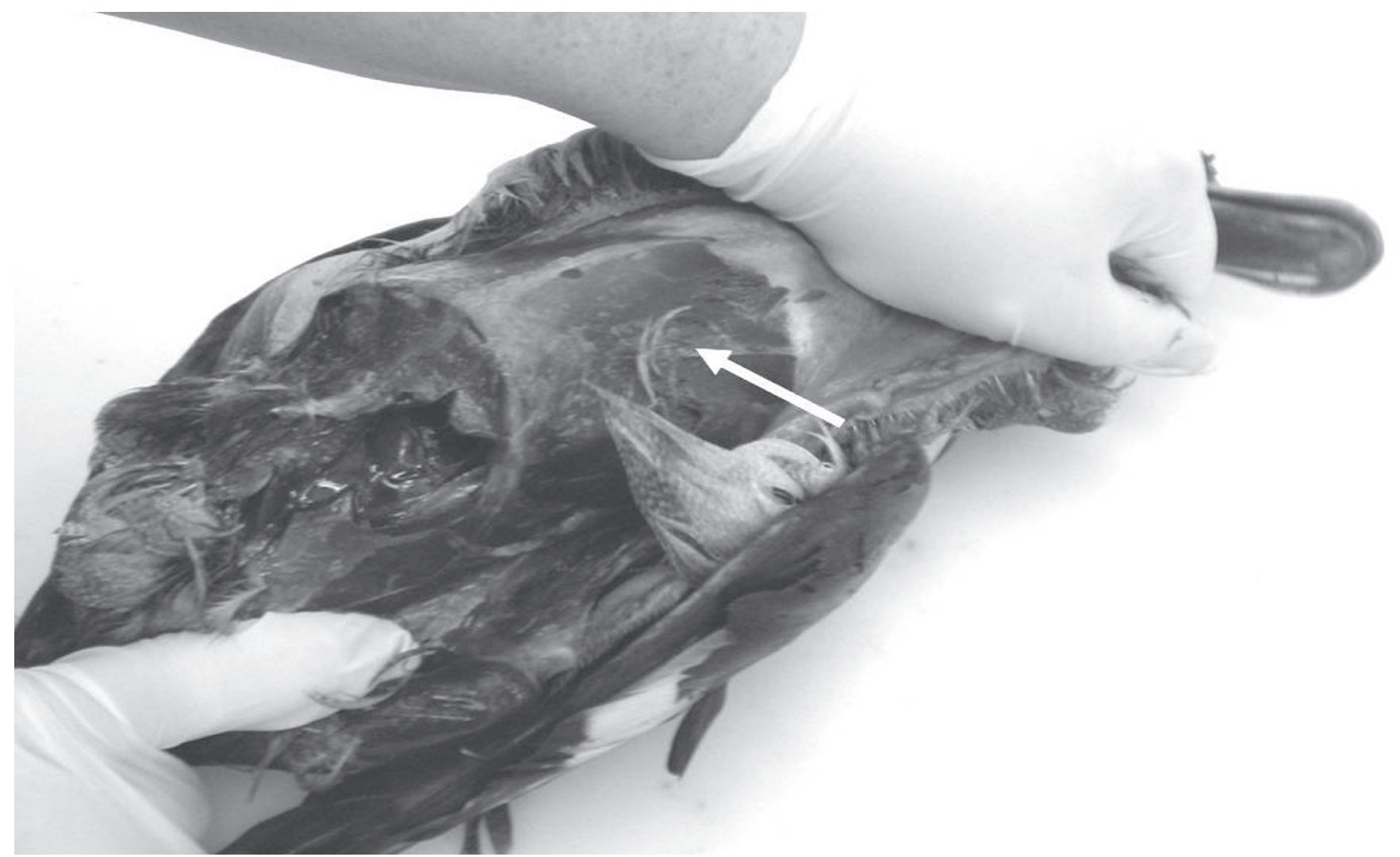

Figure 8a. Skin being peeled back towards head. Left pectoral muscle is labeled with a white arrow. 


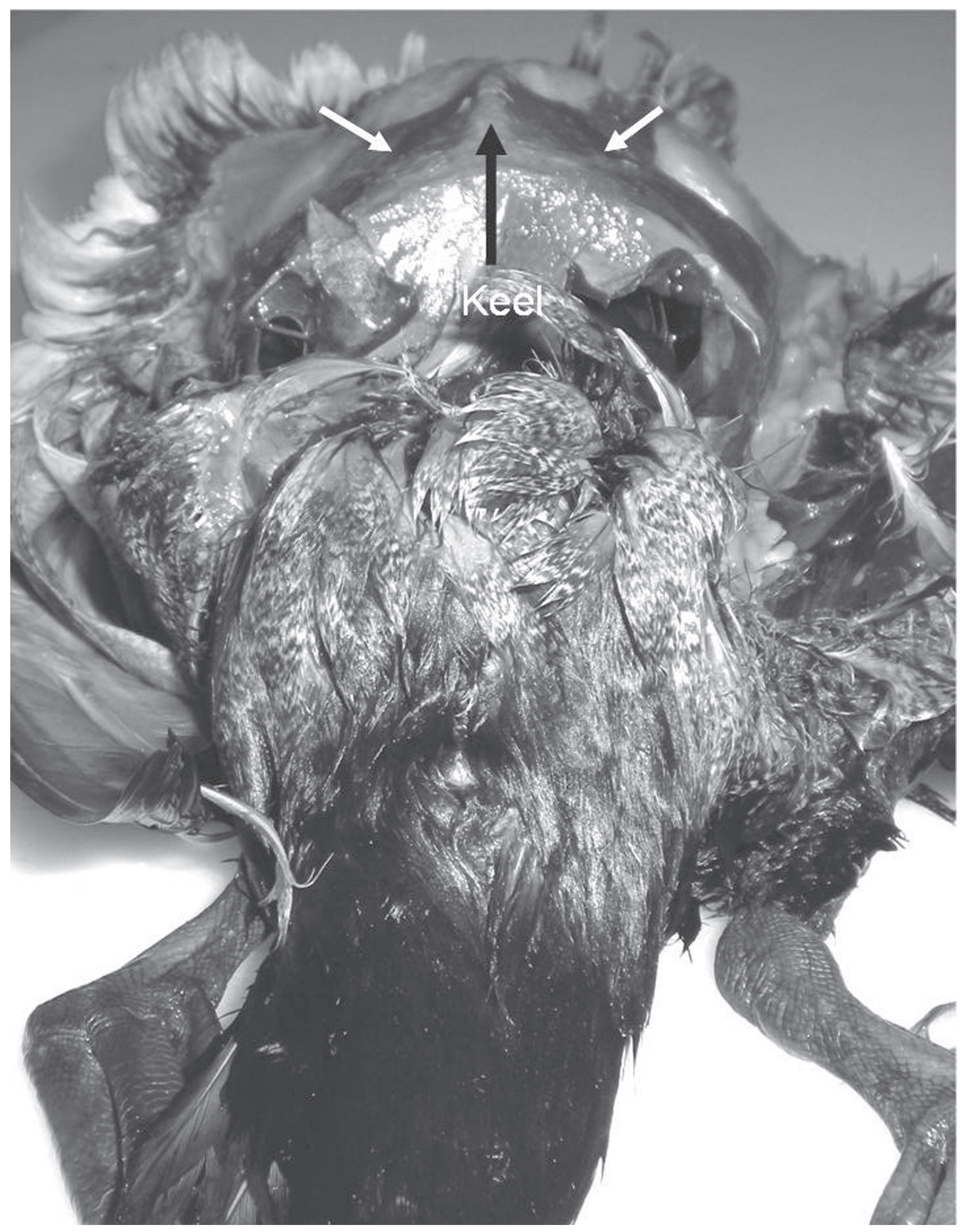

Figure 8b. View of pectoral muscles (white arrows) to aid in determination of body condition. The keel is indicated by black arrow. This bird has normal contour to the muscles. 


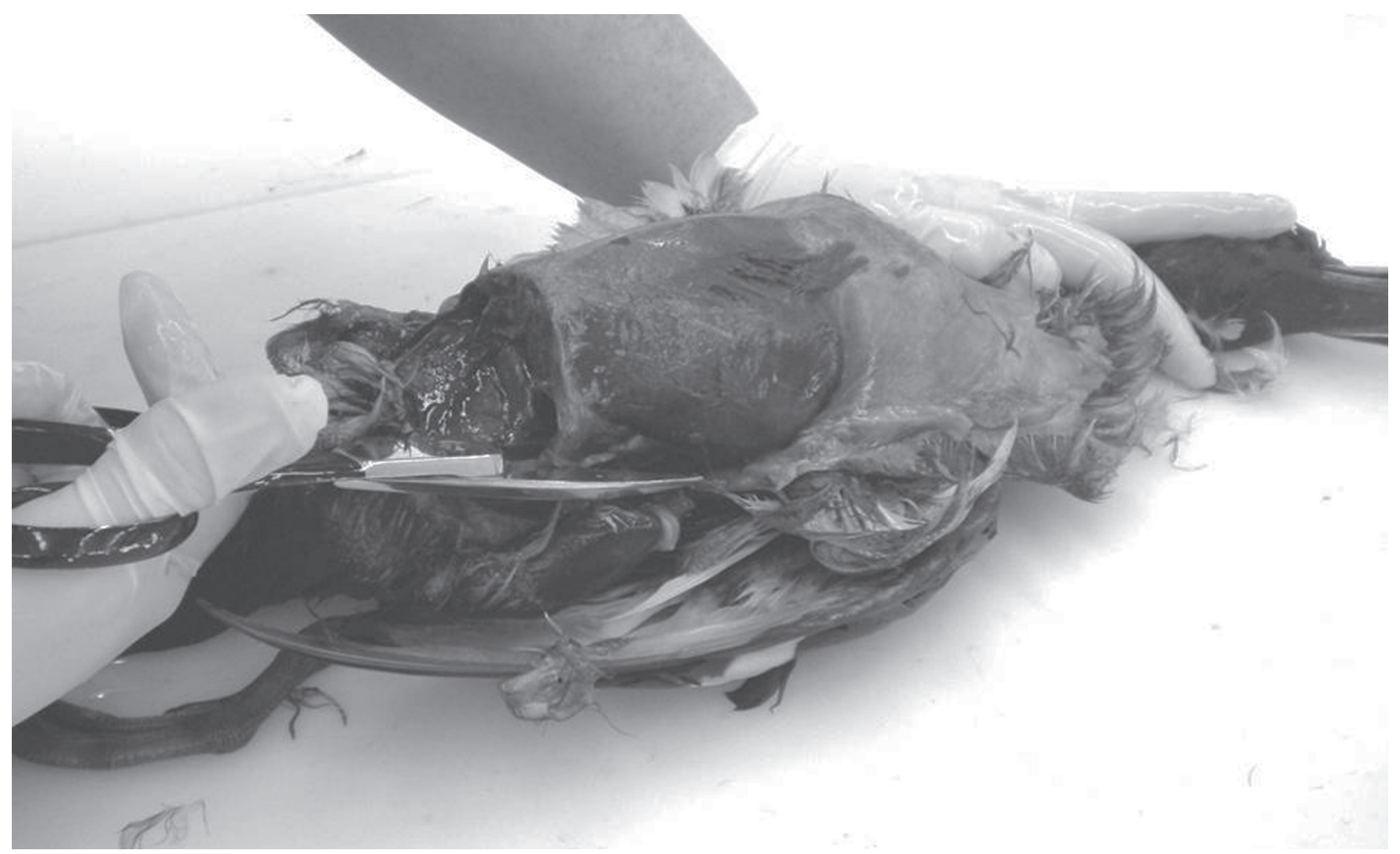

Figures $9 a, b$. Cut on both sides of sternum with poultry shears.

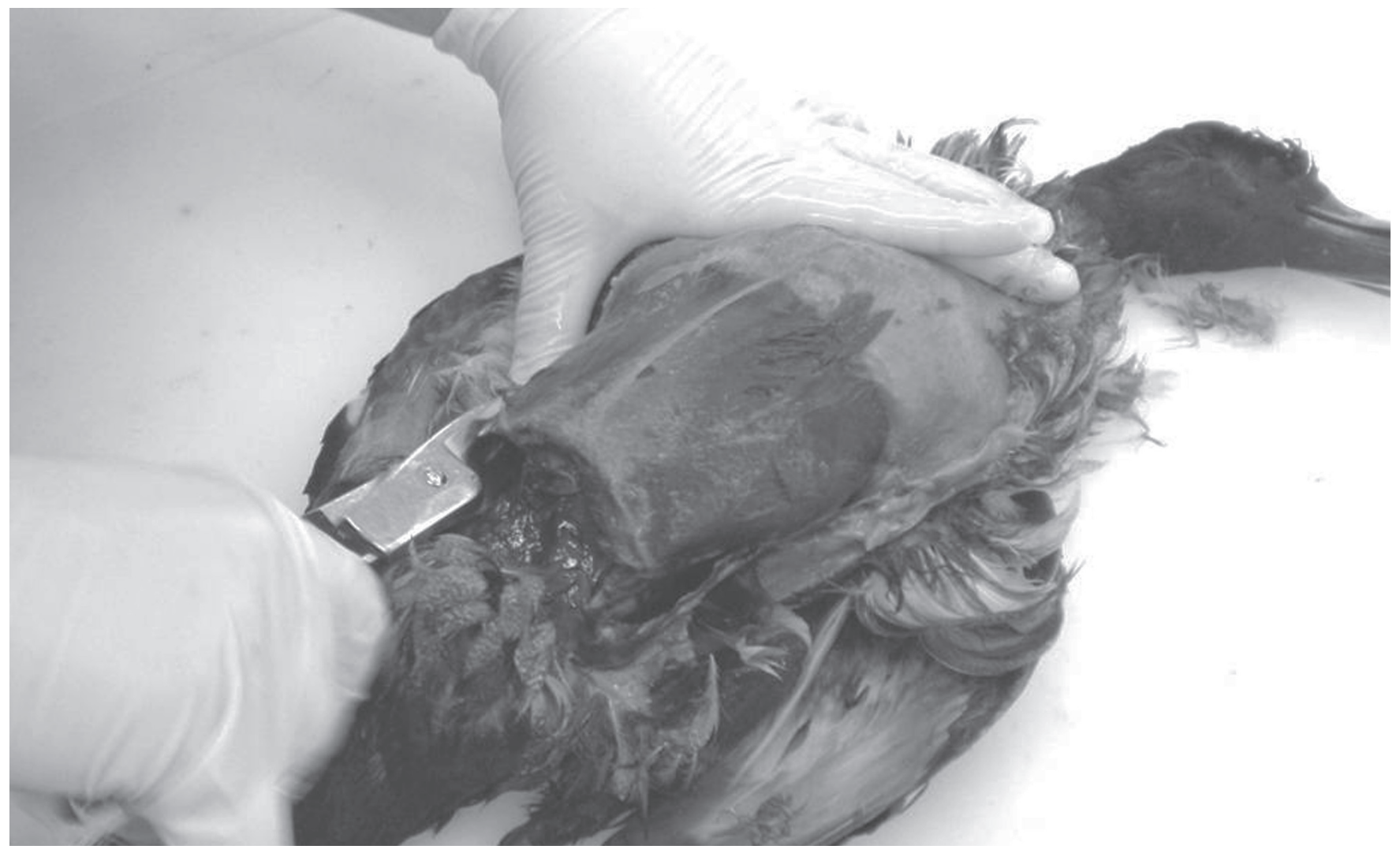

(Figure 9b). 


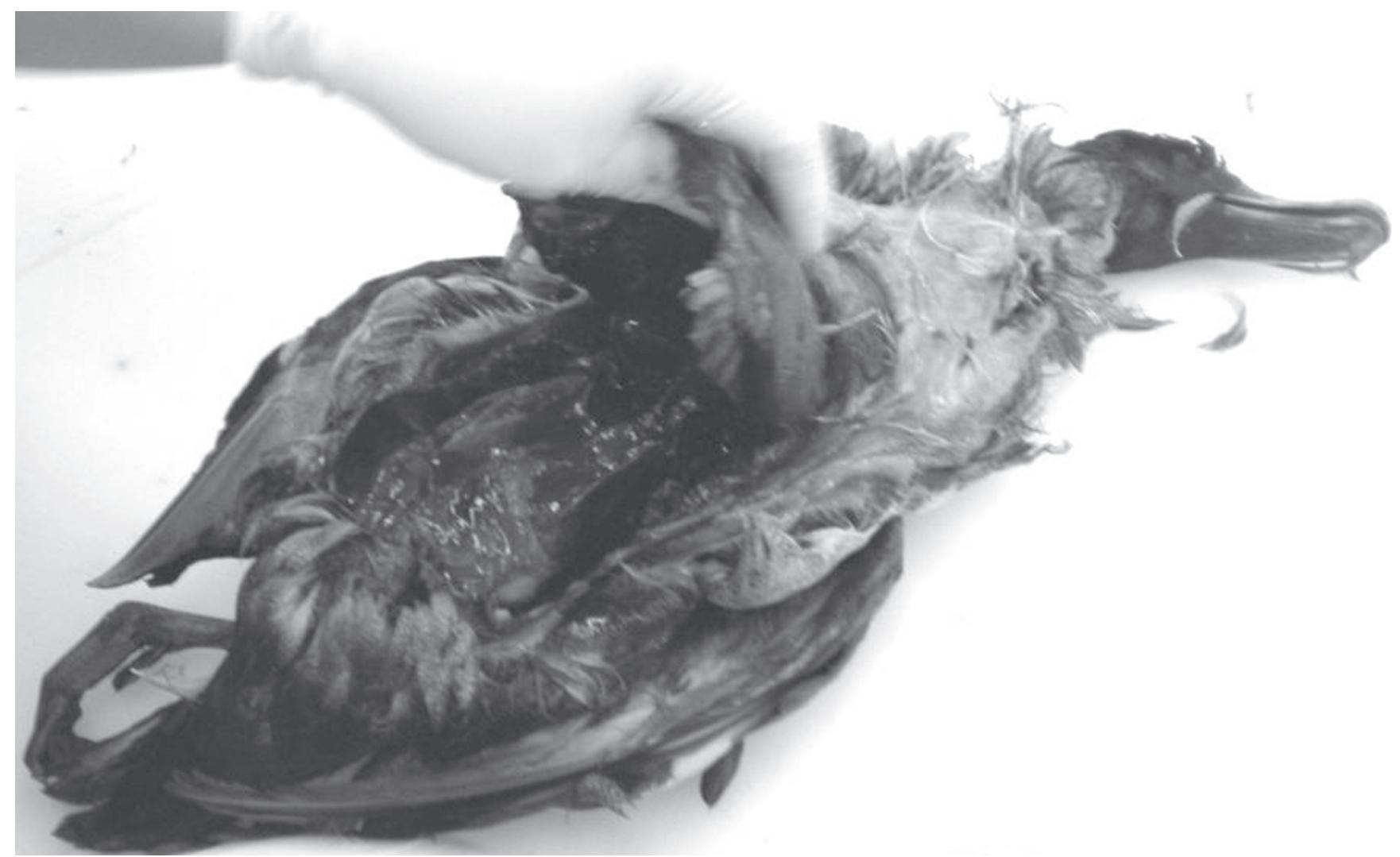

Figures $9 c, d$. Sternum is reflected back and completely removed.

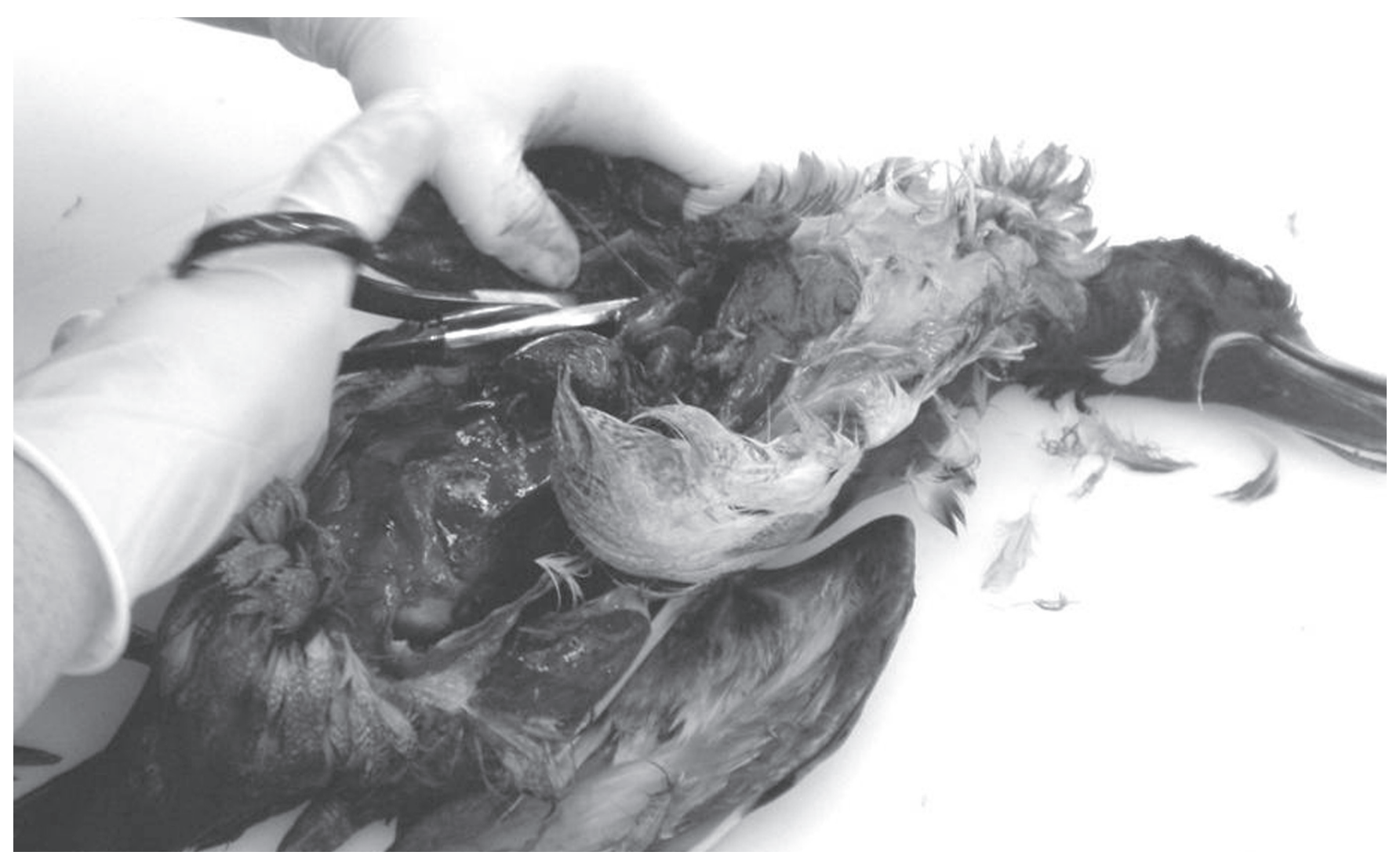

(Figure 9d). 


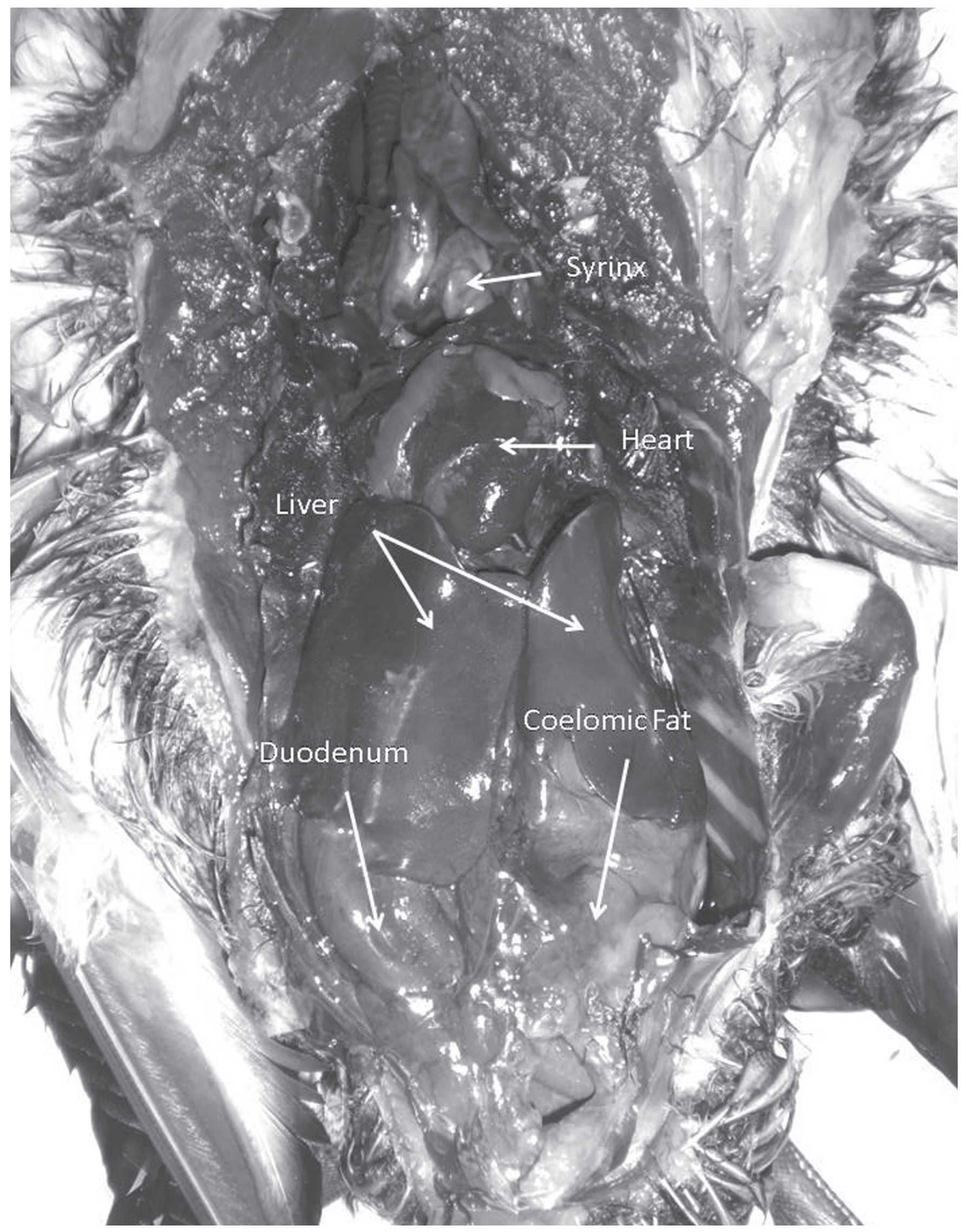

Figure 11a. Internal organs viewed after removal of sternum. 


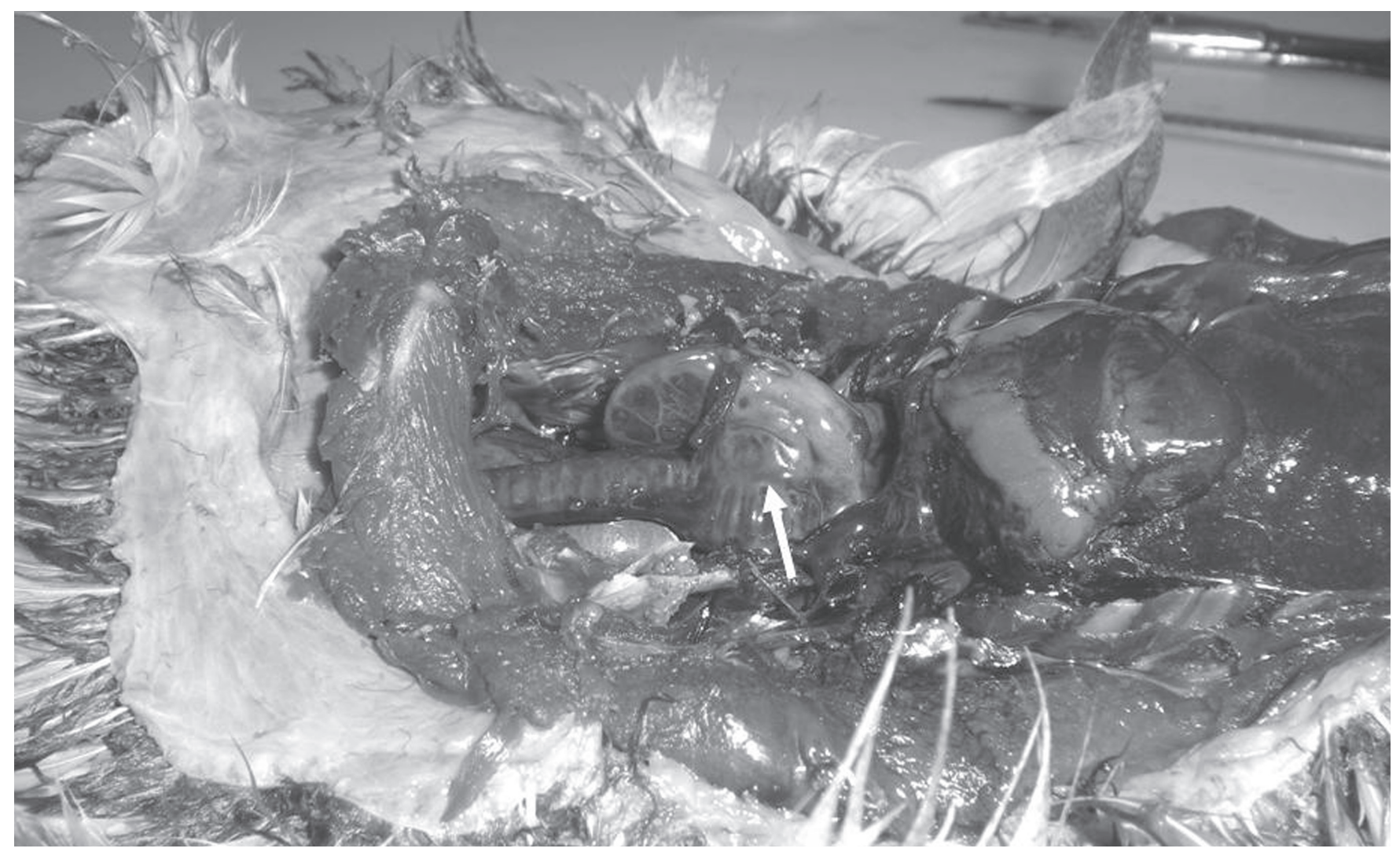

Figure 10. A large syrinx or voice box (white arrow) indicates this bird is male. The head is to the left.

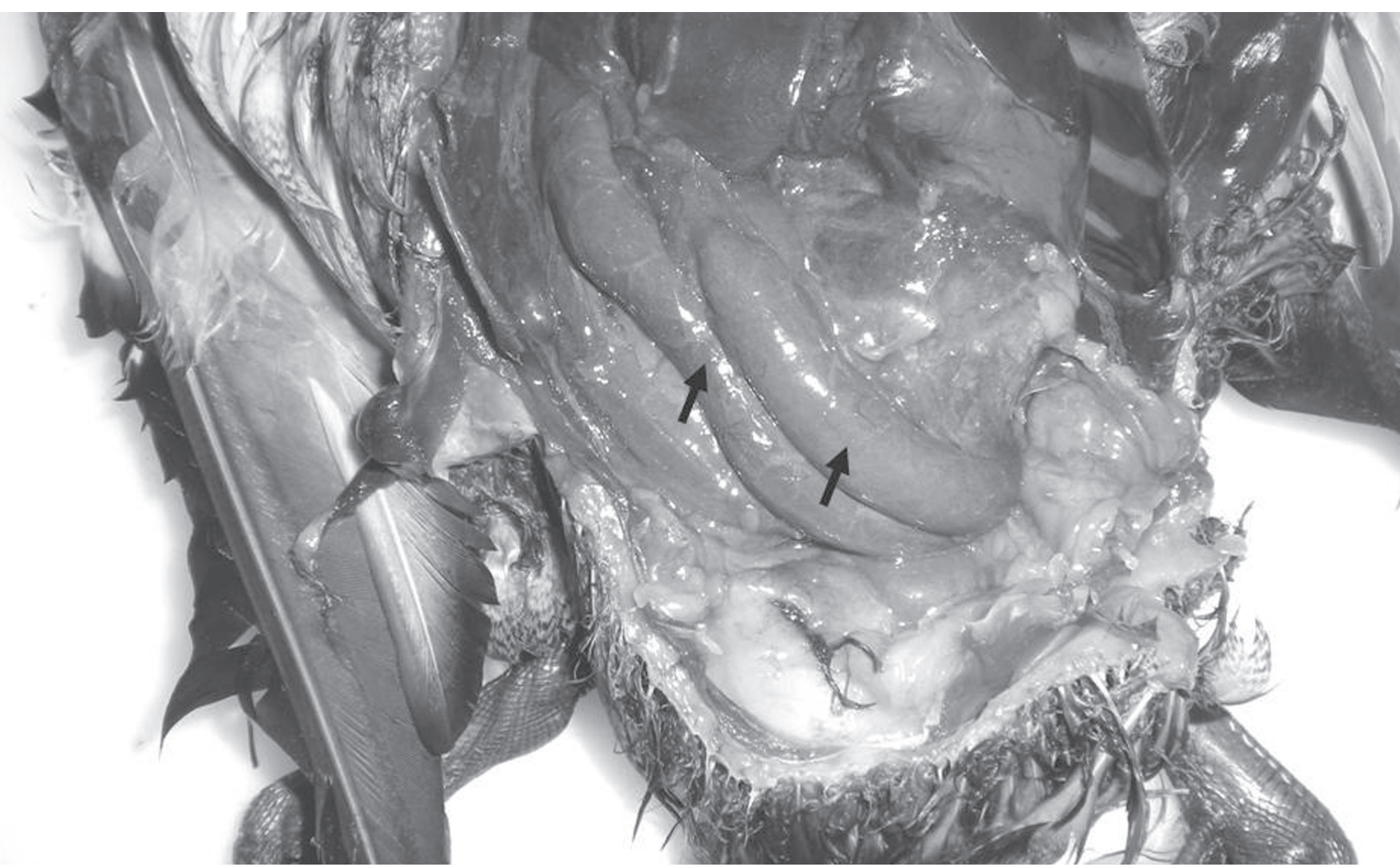

Figure 11b. Close view of the duodenum (black arrows). The pancreas sits within this loop of small intestine. 


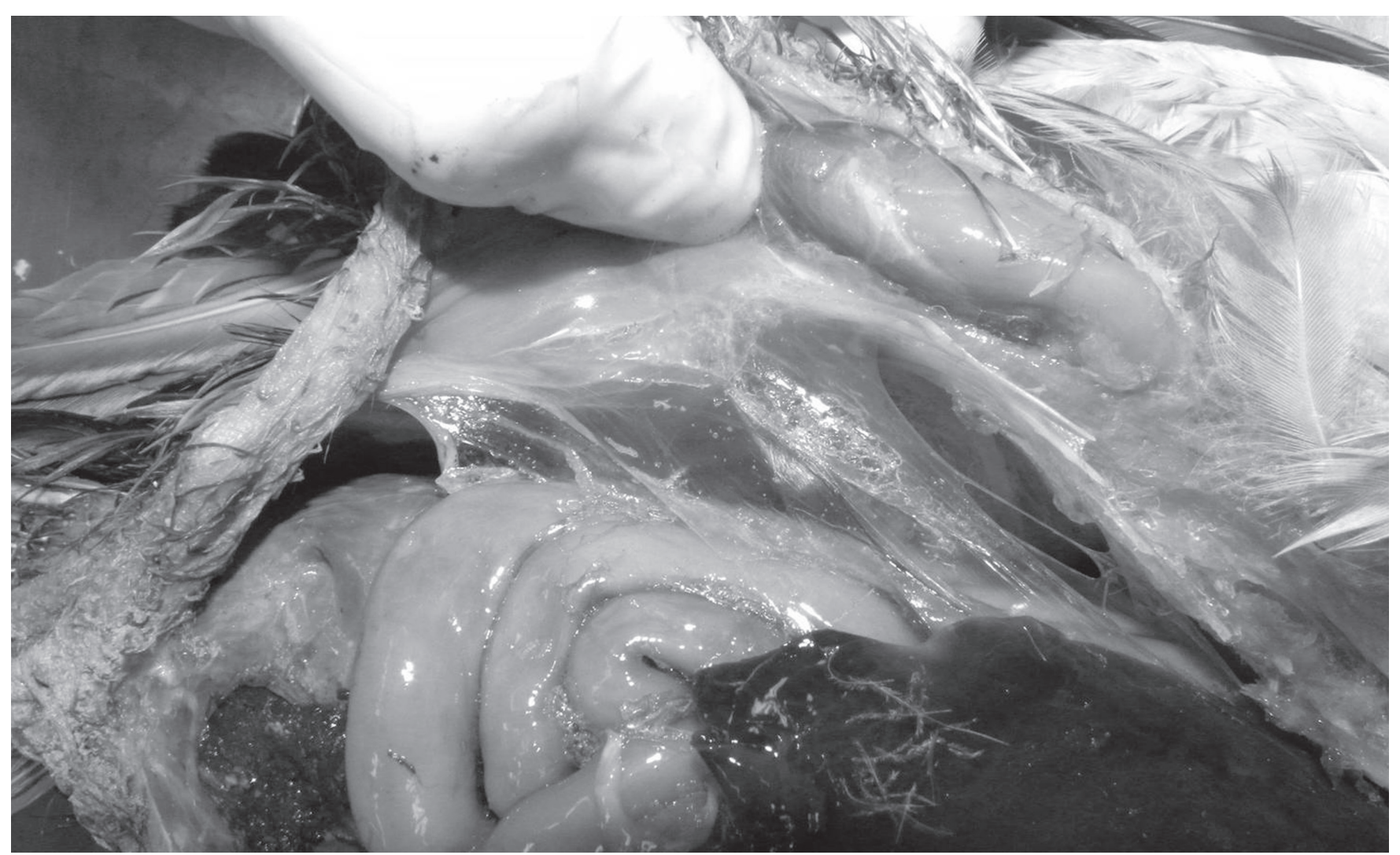

Figure 12. Mallard duck (Anas platyrhynchos) cadaver with coelomic cavity opened, prior to visceral removal. The right caudal thoracic and abdominal airsac membranes are visualized. The head is to the right.

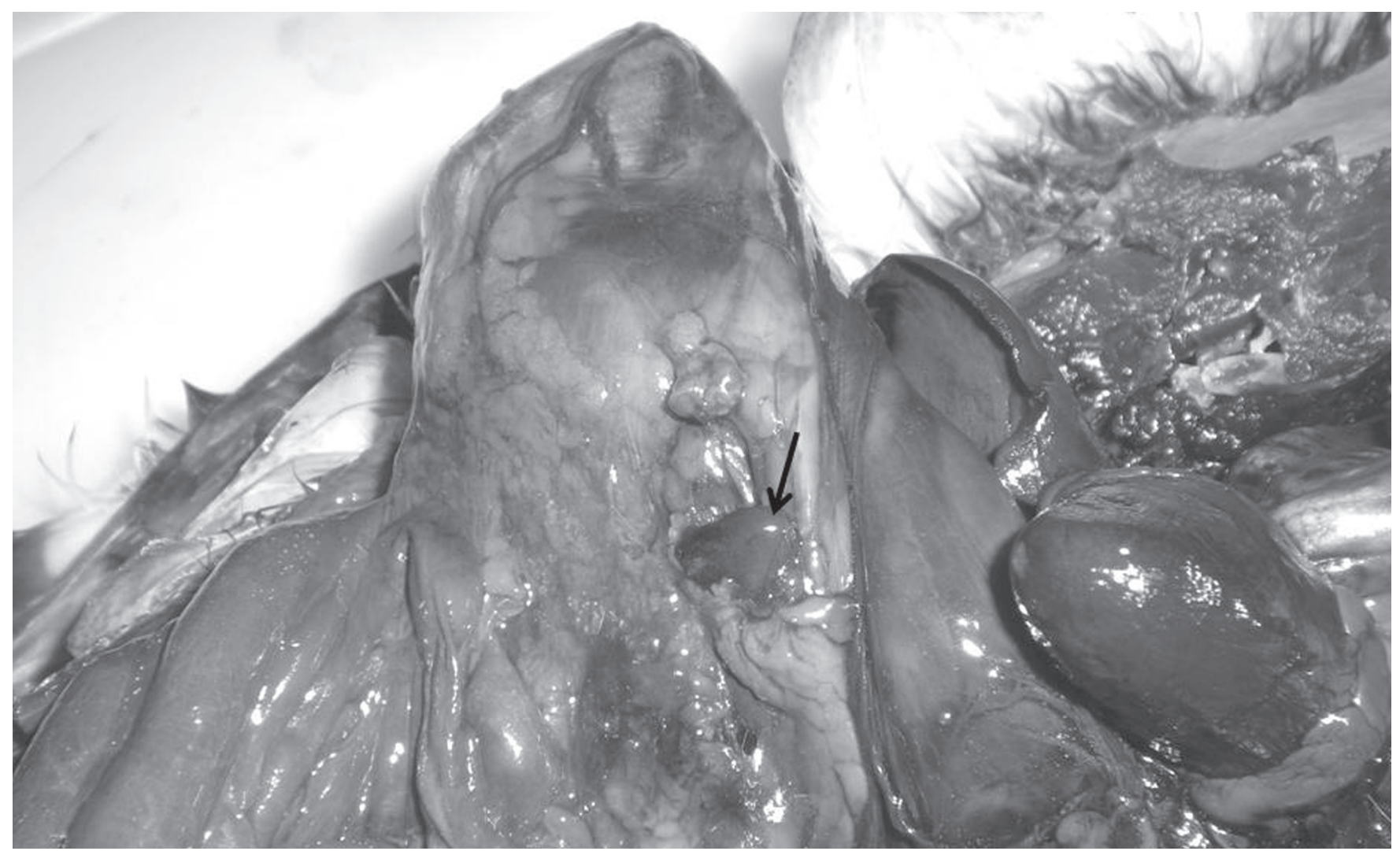

Figure 13. This is the underside of the ventriculus (gizzard), which has been flipped up towards the top of the picture. The spleen is indicated by a black arrow. The head is to the right. 


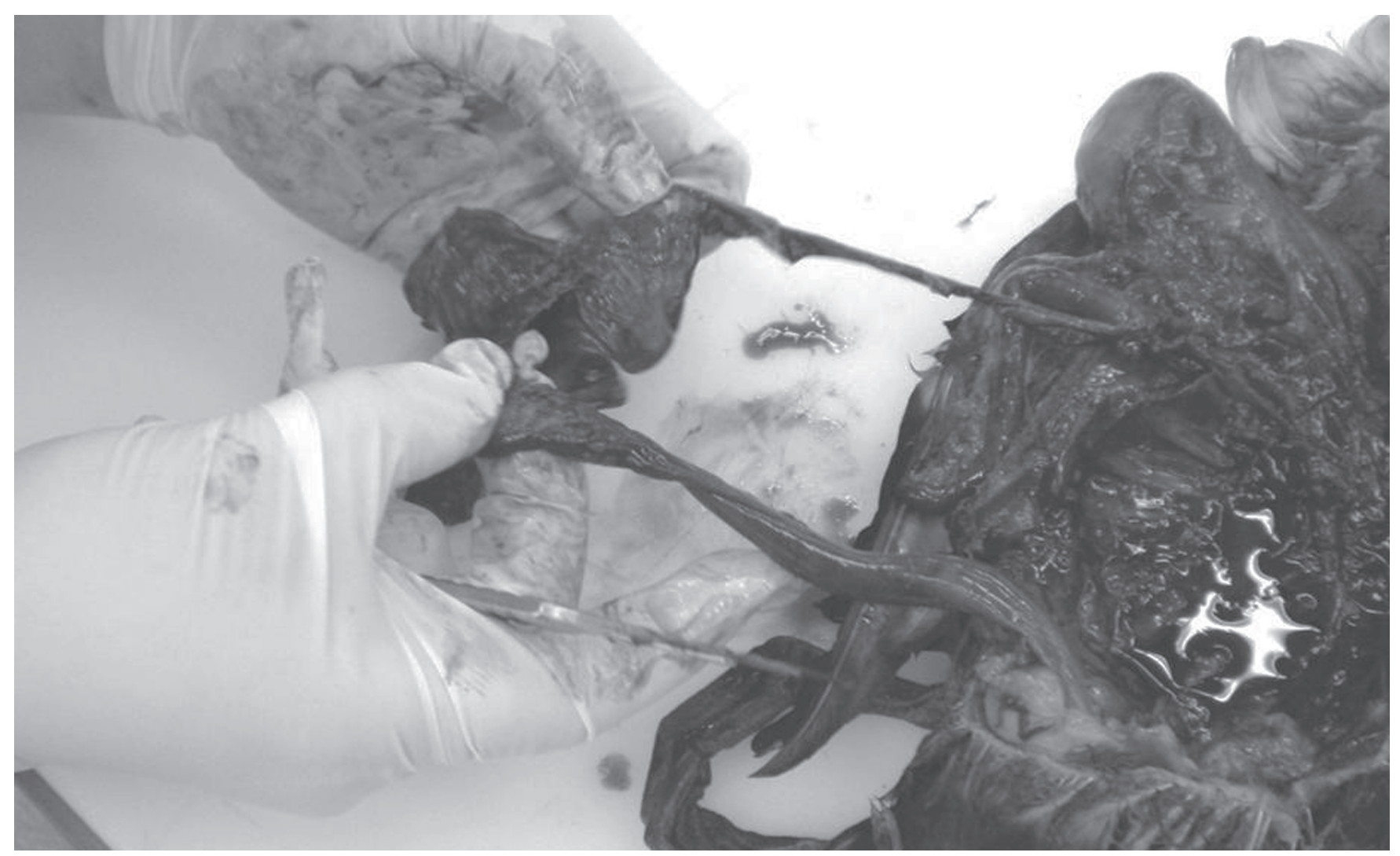

Figure 14. Exteriorization of the gastrointestinal tract.

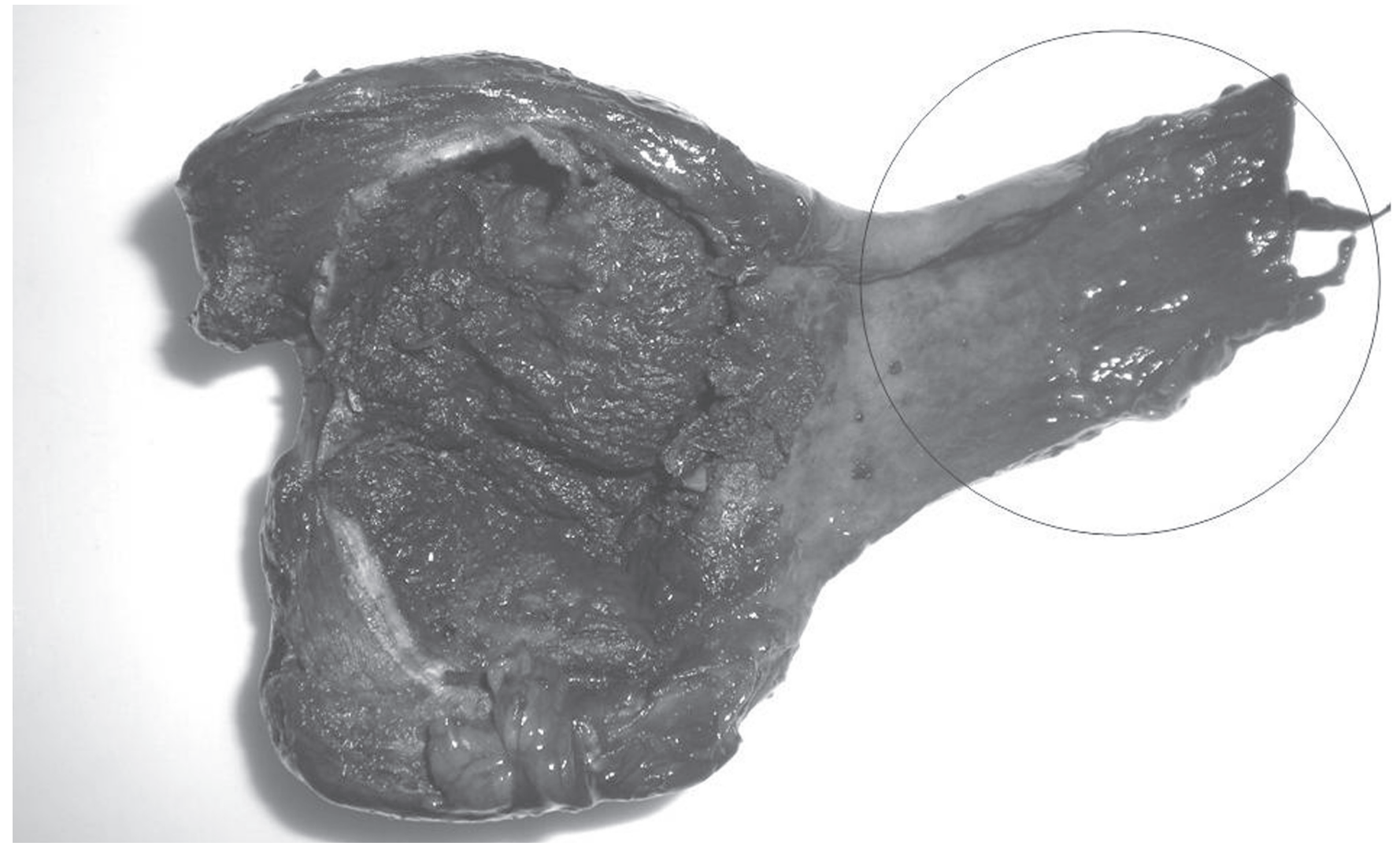

Figure 15. The opened proventriculus (black circle) and ventriculus (larger area to the left). 


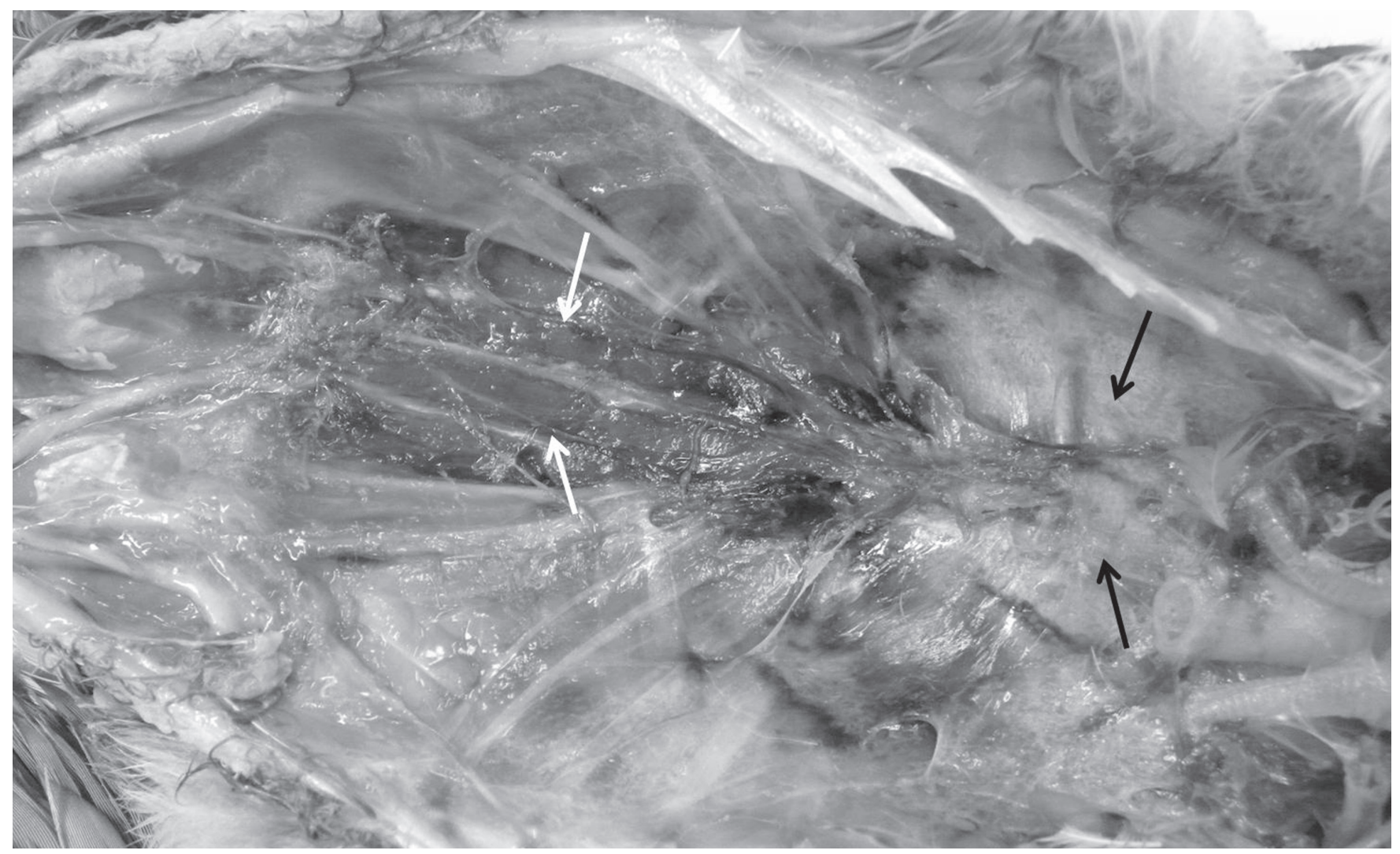

Figure 16. The coelomic cavity of a mallard with the gastrointestinal tract, liver, and heart removed. Lungs are indicated by black arrows and kidneys by white arrows. The head is to the right.

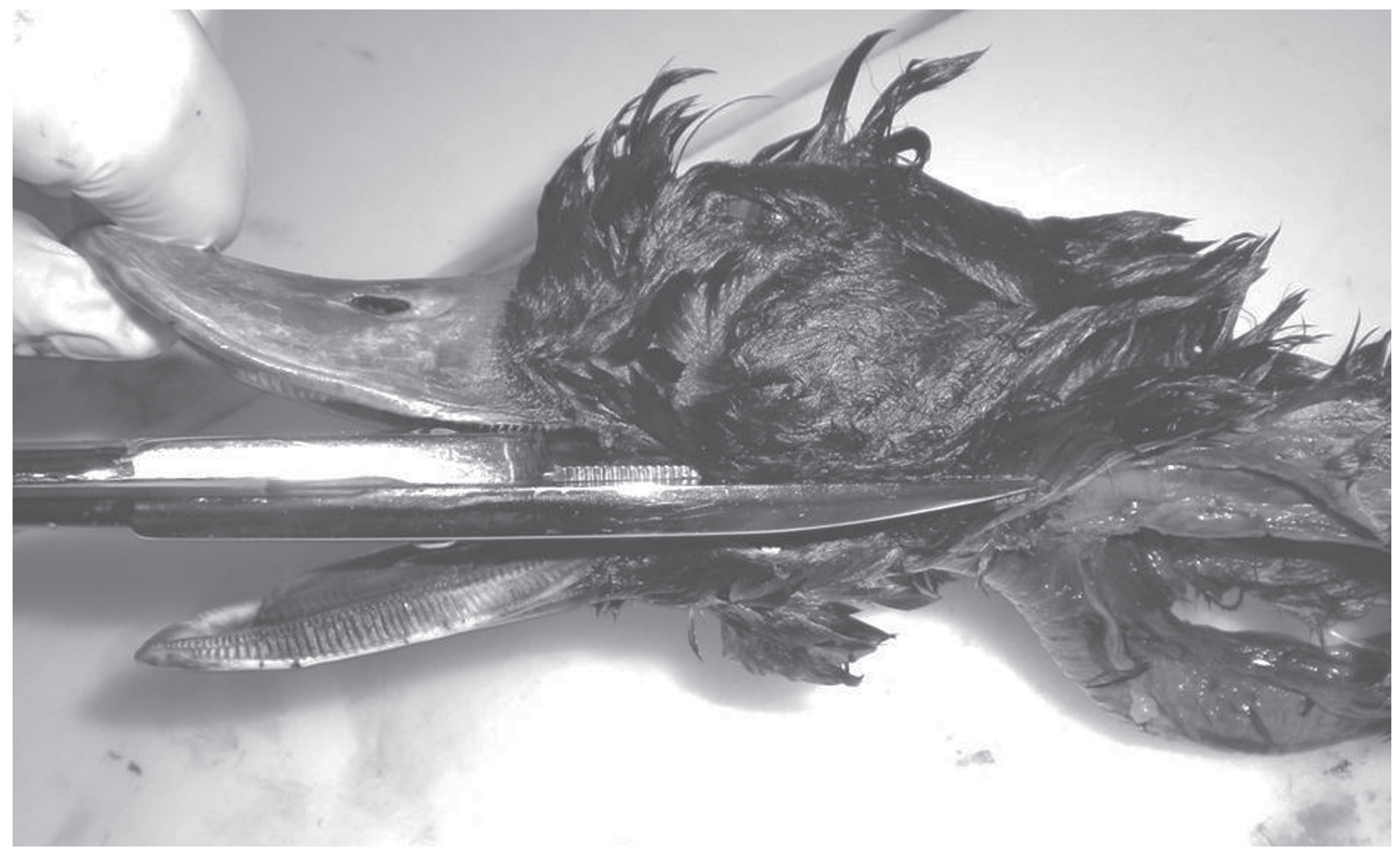

Figure 18. Cut either side of bill with poultry shears to visualize the oral structures. 


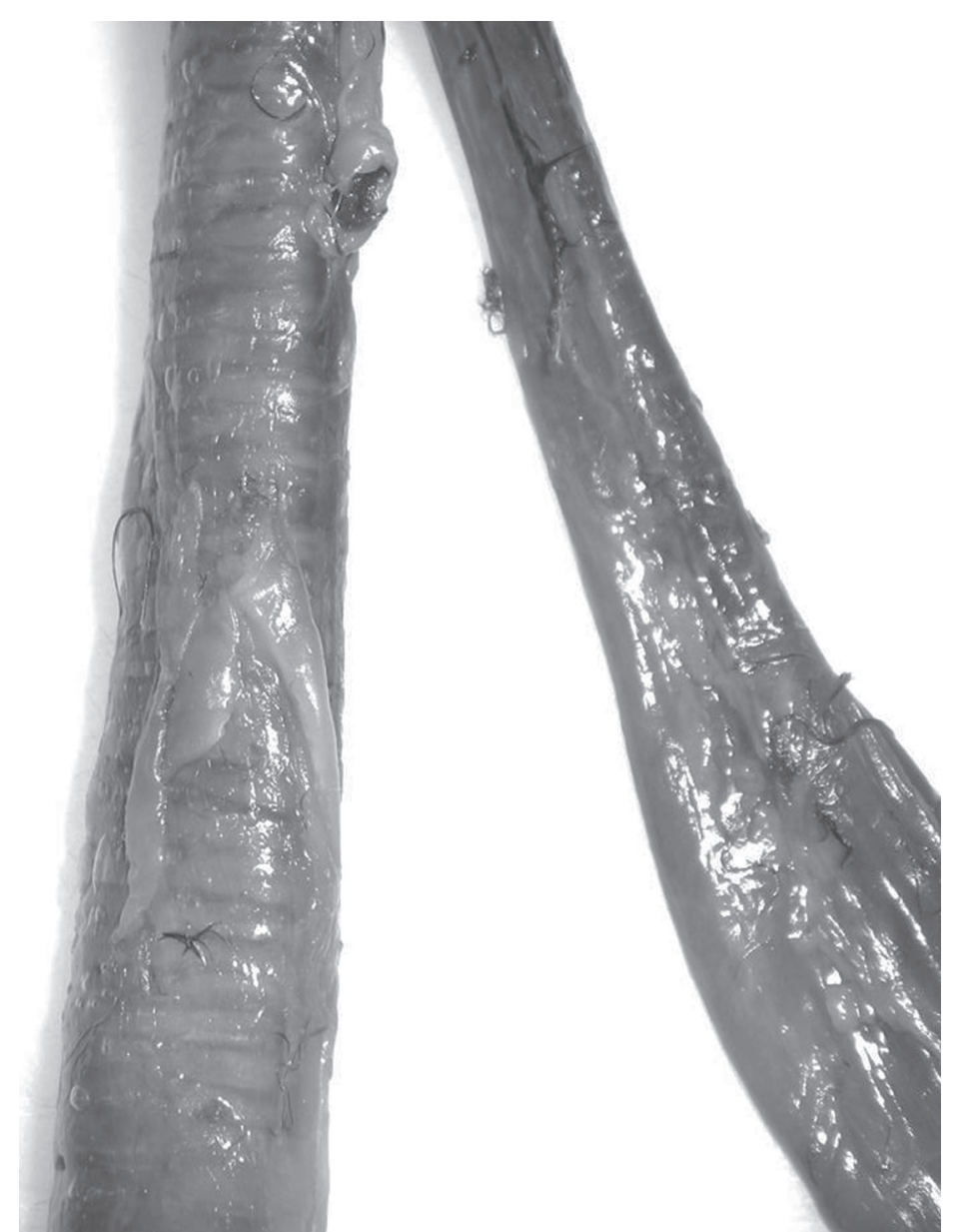

Figure 17. Trachea and esophagus with the trachea to the left. Note the cartilaginous rings of the trachea.

\section{Discussion}

Certain diseases should always be considered when performing a postmortem examination on waterfowl.

Botulism. A significant cause of mortality in ducks and other waterfowl is botulism, caused by the bacterium Clostridium botulinum type C (Rocke and Bollinger 2007). This disease mainly affects ducks and can manifest as rapid die-offs. More often, the history includes abnormal ambulation, such as wing-walking (using the wings to move forward) or flaccid paralysis of the limbs, neck, and eyelids. Birds may drown because they are unable to hold their heads up, resulting in this condition being referred to as 'limber neck.' Clinical signs are the result of a neurotoxin released by the bacteria, however visible or microscopic lesions do not develop. Intoxication is the result of ingestion of the causative bacteria often found in decomposing tissue or invertebrates such as maggots. The gastrointestinal tract may be empty at the time of postmortem examination because the food was digested and eliminated prior to the animal developing clinical signs. Conversely, maggots or fish may be present, raising the index of suspicion of botulism as the cause of death. Lesions consistent with drowning may be present (Ciganovich 1999). Presumptive diagnoses often are made based on clinical signs and absence of gross lesions; however, blood collected from freshly deceased animals is needed to detect the botulinum toxin.

Avian Cholera. Avian cholera, caused by the bacterium Pasteurella multocida, always should be suspected when massive die-offs of waterfowl species occur. Avian cholera is of significant concern for wild waterfowl populations in North America with disease occurrence in all four migratory flyways. Waterfowl and coots are affected most commonly but the disease has been reported in a variety of other species (Samuel et al 2007). Clinical signs of disease prior to death are uncommon and often there is evidence that the bird was acting normally shortly before death. The severity of lesions depends upon the duration of infection. Postmortem examination may reveal hemorrhages of various sizes on the heart and gizzard, and white to yellowish spots on the liver. A large amount of mucosal discharge from the nares may be present. The bird is usually in good body condition as indicated by large amounts of subcutaneous and visceral fat (Ciganovich 1999). When whole birds cannot be submitted to a pathologist, the heart and other affected tissues can be saved in an airtight container for bacterial culture in addition to saving tissue in formalin for routine evaluation.

Avian Influenza. Free-living waterfowl, most notably mallard ducks, serve as a natural reservoir for avian influenza (AI) (Ciganovich 1999). This virus circulates in wild populations as the low-pathogenic form and often results in subclinical infection in these birds. In 2002, reports of highly-pathogenic (HP) avian influenza in wild birds emerged from Eurasia (Stallknecht et al 2007). Signs of infection premortem are variable and include respiratory, gastrointestinal, reproductive, and neurologic abnormalities (Ciganovich 1999). Postmortem, inflammation of the pancreas may be present, as well as mild respiratory lesions and an enlarged spleen (Stallknecht et al 2007). Evaluation of the brain may reveal inflammation of brain tissue and membranes. Screening for HPAI should always be performed if the cause of death is unknown or if $\mathrm{AI}$ is suspected. A sterile, cotton-tipped applicator is used to first swab the choana (opening to nasal cavity on roof of mouth) and then the cloaca. This should be 
submitted to a pathologist for viral identification. For information on reporting sick or dead wild birds to the USDA, go to <www.usda.gov/birdflu>.

Duck Plague. Duck plague, also known as duck viral enteritis, is caused by a herpes virus and only ducks, geese, and swans are affected. Afflicted birds die rapidly and the disease mainly affects the vascular system. Postmortem findings may include hemorrhage and free blood in the gastrointestinal tract. Externally, blood staining of the vent or blood dripping from the nares may be observed. Sometimes an ulcerative 'cold sore' lesion may be seen under the tongue (Ciganovich 1999). Hemorrhage may be seen in variable amounts in the heart and liver with isolated areas of white discoloration on the liver, indicating focal necrosis (Hansen and Gough 2007). When whole birds cannot be submitted, the liver is removed, frozen, and sent to a pathologist for viral isolation.

\section{CONCLUSION}

When rehabilitating waterfowl, it is important to be aware of the potential for disease spread between patients within a facility and the introduction of pathogens to wild populations upon release. Diagnosis of the disease can save time and money by streamlining treatment and preemptively establishing prevention measures. Performing postmortem examinations of compromised individuals may reveal important information that can lead to a diagnosis. Since waterfowl are susceptible to disease outbreaks, it is especially important to intercept disease transmission via early diagnosis. Wildlife rehabilitation centers and hospitals play an integral role by being on the front lines of disease detection in an ecosystem. With the help of postmortem examinations, wildlife rehabilitators can contribute to monitoring the health of waterfowl and the ecosystems in which these birds live.

\section{LITERATURE CITED}

Ciganovich, E. A., editor. 1999. Field Manual of Wildlife Diseases. US Geological Survey: Madison, WI.

Halliday, J. E. B., A. L. Meredith, D. L. Knoebel, D. J. Shaw, B. M. Bronsvoort, and S. Cleaveland. 2007. A Framework for Evaluating Animals as Sentinels for Infectious Disease Surveillance. Journal of the Royal Society Interface. 4(16): 973-984.

Hansen, W. R., and R. E. Gough. 2007. Duck Plague (Duck Virus Enteritis). Pp. 87-107 in Infectious Diseases of Wild Birds (N. J. Thomas, D. B. Hunter, C. T. Atkinson, eds.). Blackwell Publishing: Oxford, England.
McCluskey, B. J. 2003. Use of Sentinel Herds in Monitoring and Surveillance Systems. Pp. 119-133 in Animal Disease Surveillance and Survey Systems: Methods and Applications (M. D. Salman, ed.). Iowa State Press: Ames, IA.

Porter, S. L. 2001. Wildlife Under the Microscope [CD-ROM]. Blue Ridge Community College: Weyer's Cave, VA.

Rocke, T. E., and T. K. Bollinger. 2007. Avian Botulism. Pp. 377-416 in Infectious Diseases of Wild Birds (N. J. Thomas, D. B. Hunter, C. T. Atkinson, eds.). Blackwell Publishing: Oxford, England.

Samuel, M. D., R. G. Botzler, and G. A. Wobeser. 2007. Avian Cholera. Pp. 239-269 in Infectious Diseases of Wild Birds (N. J. Thomas, D. B. Hunter, C. T. Atkinson, eds.). Blackwell Publishing: Oxford, England.

Schmidt, R. E., and D. R. Reavill. 2003. A Practitioner's Guide to Avian Necropsy [CD-ROM]. Zoological Education Network: Lake Worth, FL.

Sleeman, J. M., and E. E. Clark. 2003. Clinical Wildlife Medicine: A New Paradigm for a New Century. Journal of Avian Medicine and Surgery. 17(1): 33-37.

Stallknecht, D. E., E. Nagy, D. B. Hunter, and R. D. Slemons. 2007. Avian Influenza. Pp. 108-130 in Infectious Diseases of Wild Birds (N. J. Thomas, D. B. Hunter, C. T. Atkinson, eds.). Blackwell Publishing: Oxford, England.

Stitt, T., J. Mountifield, and C. Stephen. 2007. Opportunities and Obstacles to Collecting Wildlife Disease Data for Public Health Purposes: Results of a Pilot Study on Vancouver Island, British Columbia. The Canadian Veterinary Journal. 48(1): 83-87, 90-98.

Trocini, S., C. Pacioni, K. Warren, J. Butchler, and I. Robertson. 2008. Wildlife Disease Passive Surveillance: The Potential Role of Wildlife Rehabilitation Centers. Proceedings of the National Wildlife Rehabilitation Conference: Canberra City, Australia.

Wobeser, G. A. 1997. Diseases of Wild Waterfowl, 2nd edition. Plenum Press: New York, NY.

Woodford, M. H., ed. 2001. Quarantine and Health Screening Protocols for Wildlife Prior to Translocation and Release into the Wild. IUCN Species Survival Commission's Veterinary Specialist Group (Gland, Switzerland), the Office of International des Epizooties (Paris, France), Care for the Wild (England), and European Association of Zoo and Wildlife Veterinarians: Switzerland. 
Work, T. M. 2000. Avian Necropsy Manual for Biologists in Remote Refuges. US Geological Survey, National Wildlife Health Center Hawaii Field Station. Available from: <http://www.nwhc.usgs.gov/publications/ necropsy_manuals/Avian_Necropsy_ Manual-English.pdf/>. (NRR

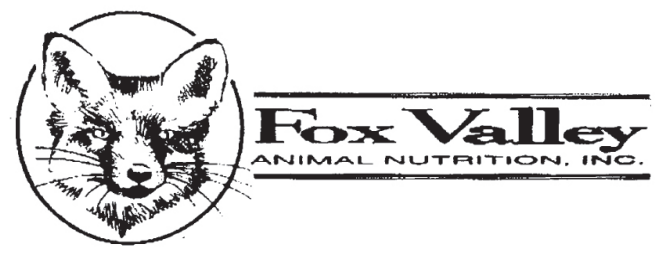

DAY ONE FORMULAS ARE SPECIES SPECIFIC MILK REPLACERS FOR DOMESTIC, EXOTIC, AND WILDLIFE MAMMALS USING HIGH QUALITY INGREDIENTS. ALSO OFFERING:

LA 200 LACTOBACILLUS ACIDOPHILUS

DIA STAT 200 to normalize stool consistency ELECTRO STAT 200 electrolyte

ULTRA BOOST high fat cream additive ULTRA WEAN weaning formula (all in powder form)

CATAC NURSER BOTTLES AND TEATS

SNUGGLE SAFE microwaveable heat pads O-RING SYRINGES

Visit our web site: foxvalleynutrition.com sales/tech: 800-679-4666 fax 815-578-4240

\section{Manual of Exotic Pet Practice}

This text covers common species, nutrition, and common disease prevention on many exotic pets including:

-Birds

-Amphibians

- Rabbits

-Lizards

Manual of Exotic Pet Practice also includes an entire section of over 35 pages devoted to Wildlife!

Also includes over 400 color photos, information on CPR, drugs, and supportive care, and reviews of common surgical procedures.
By Mark A. Mitchell

and

Thomas N. Tully, Jr.

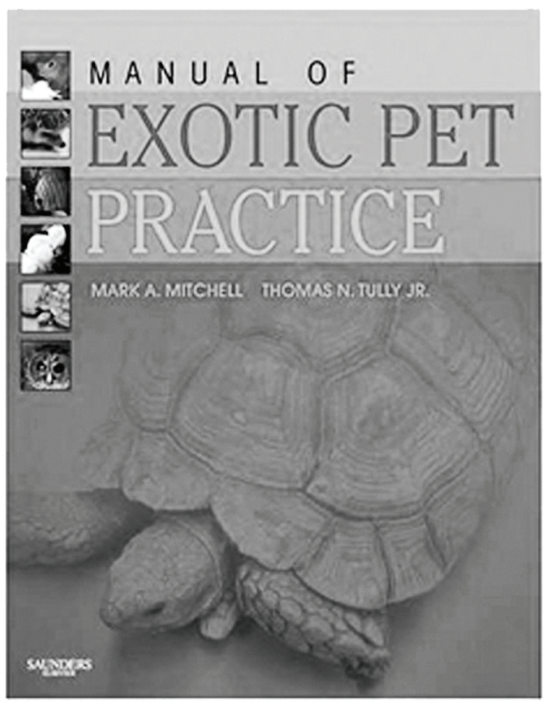

Price for Manual of Exotic

Pet Practice is $\$ 96.25$

(postage and handling included).

Pricing for shipment outside of the continental US may vary. Please call for rates.

Please send check or money order in US funds along with a note stating what you are purchasing to:

NWRA Sales

2625 Clearwater Rd, Ste. 110

St. Cloud, MN 56301

Or visit us online at: www.nwrawildlife.org 